\title{
Durable Goods and Energy in RBC: An Endogenous Multisectoral Model
}

\author{
Philip Bergmann
}




\title{
Durable Goods and Energy in RBC: An Endogenous Multisectoral Model
}

\author{
Philip Bergmann*
}

Bielefeld University

\author{
December 19, 2018
}

\begin{abstract}
We have constructed a RBC model where energy is endogenously minded. It is generated within the model from fossil intermediate and renewable energy resources and consumed by final good production and households. Furthermore, households can invest in a durable good to avoid exaggerated disruptive investment dynamics. By estimating the model using Bayesian techniques and with data from the German economy, we find a complementary relationship between durable goods and energy consumption in the household sector as well as between physical capital and energy consumption in the final good sector.

Furthermore, a TFP shock in the (final and intermediate) energy sectors has a larger effect on durable good purchases than on capital investments in the final good production. Nevertheless, even with endogenous price determination of energy, TFP in final good production is still the major contributor to business cycle formation in a classical framework. In an extension, we show that despite of allowing the replenish the constrained fossil stock, the dynamic responds of the variables do not deviate from the baseline model.
\end{abstract}

JEL Codes: D58, E32, Q43

*Department of Business Administration and Economics, Bielefeld University, Universitätstrasse 25, 33615 Bielefeld, Germany; e-mail: pbergmann@uni-bielefeld.de 


\section{Introduction}

A stable supply of energy is essential to ensure a durable and substantial economic development, and to guarantee long-run welfare. Real life examples where energy supply has been unstable, due to a weak energy infrastructure and energy sector, are known from developing countries, where economies struggle to flourish. Such struggling economies' production sectors are often unable to produce sufficient final goods, either to be consumed or exported, and consequently they are unable to participate in global growth. At the same time, events such as the oil crises in the 1970s and 1980s show that developed countries are not immune to similar problems. Due to the negative consequences that accompanied these crises, many countries started moving towards alternative ways of organizing their energy sector and energy usage, to minimize the dependence on singular energy resources, and thus to minimize the risk. A more efficient usage of energy, at the same time beneficial for productivity in general, is just one way to achieve this. Another was is to substitute finite energy resources by alternative and locally produced resources. Macroeconomic models, in particular those investigating business cycles in the short term, have either focused on one single energy resource, or not taken energy into account at all. Those models who do consider energy in the production process, propose that shocks in the supply or price formation of energy resources are exogenous.

The aim of this paper is to deepen the existing literature by allowing for energy sectors distinguishing finite and renewable energy resources. Moreover, the price formation of energy and intermediate energy resources is endogenously determined. Furthermore, we investigate whether there is a complementary relationship within the bundle of durable goods and energy in the household's utility function and capital and energy in the final goods production function. The paper investigates the effects of stochastic technological progress on the production side, in particular in the energy sectors. In particular, our paper studies the dynamics within a model calibrated to match the German economy.

To this end, we construct a RBC model of a closed economy with three main sectors. Energy, as a further input good, is consumed by households and used in the production process of final goods. Furthermore, we distinguish between two types of consumable goods: durable goods and non-durable goods where the former can only be used in combination with energy (the same holds for capital in the production function of final goods). This is motivated by Dhawan and Jeske (2008) who analyze the role of durable consumption goods in a business cycle. They model energy, which explicitly enters the model in the utility as well as in the production function, as an exogenous variable which is stochastically affected by shocks. However, in the present paper, energy is not only endogenized but also generated by a combination of different resources, namely a infinite one and a finite one. Our extension allows for a transition from the non-renewable resource to the backstopping resource due to a change in relative marginal costs. 
In a further extension, we allow for a constrained replenishment of the finite resource stock. As in Gross et al. (2013), investments in R\&D transform resources which are not accessible with previously technology to reserves which are available as an input factor to produce intermediate energy. But opposite to (Gross et al., 2013), capital and $\mathrm{R} \& \mathrm{D}$ is completely supplied by domestic households and the price of intermediate energy generated by the non-renewable energy sector is determined endogenously. By doing so, we investigate how dynamics of TFP shocks deviate from the benchmark model in case of depletion and exploration.

In our estimated RBC model, we find a complementary relationship between durable goods and energy consumption in the household sector as well as between physical capital and energy consumption in the final good sector. Furthermore, a TFP shock in the (final and intermediate) energy sectors has a larger effect on durable good purchases than on capital investments in the final good production going along with results from Dhawan and Jeske (2008). Nevertheless, even in the model at hand with endogenous price determination of energy, TFP in final good production is still the major contributor to business cycle formation. Moreover, despite of allowing the replenish the constrained fossil stock in an extension, the dynamic responds of the variables do not deviate from the basic model.

The paper is organized as follows. Firstly, we give an overview about existing research. Secondly, we present the model, followed by the derivation of the equilibrium. In chapter five, we discuss the calibration of parameter, the estimation methods which will be applied as well as the posterior results of the estimated parameters. In chapter 6, we discuss the numerical results and the accuracy to fit the data. Chapter 7 analyzes the dynamic results of the model, caused by technological progress in the production function. In chapter 8 , a shock decomposition of GDP is taken to analyze the weighting of the individual shocks. In chapter 9, we conclude.

\section{Literature}

The amount of literature dealing with the role of energy and similar resources in a theoretical framework is quite extensive. Moreover, the term "energy" is taken quite vague by often describing specifically oil as a finite resource. In general, economists analyze the effects of energy in macroeconomic models through different transmission channels which present the reciprocal relations of energy and other macroeconomic components supported by evidence from literature (Bernanke et al., 1997; Kilian, 2008; Herrera, 2018). In earlier studies, energy has been mainly present on the supply side. However, its degree of importance is differently valued. In the course of time, two strings of theories have been established with contradictory views about the effect and use of energy in the macroeconomic environment. 
On the one side, supporters of the "conservation hypothesis" take the view that energy can simply be substituted for alternative input factors. Moreover, technological progress can ease this process and leaves energy as a non-essential component. Hence, energy scarcity would not have negative effects on the economy. This allows economic growth even in the presence of a scarce energy resource where non-finite alternatives act as possible substitutes (Solow, 1974; Stiglitz, 1974; Tobin et al., 1980).

On the other side, the "growth hypothesis" promotes scarce resources as the limiting factor for economic growth due to its binding supply constraint. Considering finite energy as the primary resource in production, this theory is particularly supported by ecological economists (Stern, 2011). Possible substitutes such as capital and labor cannot fully take effect in the production process without energy. Consequently, the latter constitutes a complementary product. In the present paper, when considering the short term, we follow this theory as a possibility of substitution by other components which is constrained by time. To be more precise, investments are needed to enforce these strategy changes. The conservation hypothesis is not completely neglected. The reason is that we allow for different types of energy resources, finite and renewable, and consequently some degree of substitution between them.

Frequent literature who analyzes the theoretical relationship of energy with other macroeconomic variables often include RBC models. In principle, these models investigate the external influence through shocks on the modeled economy and decompose the effects on its variables. But despite of the popularity of RBC models that stems from its close to real-life predictions, the role of aggregate technology shocks is controversial. Several researchers such as Plosser (1989) and McCallum (1988) have agreed that some of the facts that characterize economic variations are successfully explained by RBC models. However, it remains a constraint that a number of important issues, such as shocks, that should explain variations in the business cycle have stayed unsolved, or that evidence for them is too fragile to be credible. One criticism is the role of the Solow residual which is often identified as the main source of aggregate fluctuations in the model. On the one side, the nature of technological shocks often remains open. On the other side, the Solow residual includes unexplained behaviors such as energy price shocks that are not necessarily linked to productivity which leads to overestimation of the productivity factor.

In this context, McCallum (1988) has identified energy as an essential factor on the supply side which contributes to fluctuation to which less attention is paid. In one of the subsequent papers, Kim and Loungani (1992) analyze a RBC model with respect to exogenous energy price changes. By implementing energy in the production function as a further independent input factor, next to the usual inputs such as capital and labor, this allows to extend the source of possible fluctuations affecting total output. In their model, the relative price of energy is modeled as an exogenous stochastic process. All 
structural parameters base on the US economy and are chosen in line with microeconomic evidence and certain historical averages. However, the results are in line with those of macro-economists who neglect the impact of shocks by energy factors on an economy. TFP is still the main driver of output volatility while objections such as those by Tobin et al. (1980) who noted that the share of energy in GNP is too small to generate strong aggregate impacts are confirmed. On the one side, this leads Kim and Loungani to assume prices and wages to be perfectly flexible which is contrary to empirical studies which derive strong impacts of energy on real variables due to the implementation of some degree of rigidity in prices and wages (Mork and Hall, 1980; Black, 1985). On the other side, energy prices are completely exogenously determined and moreover exclusively affecting the production side. In the present paper, the latter assumption is changed by allowing for energy production determined from within the model and used by the production and consumer side.

To meet the critics, researcher have considered different approaches to implement energy in RBC models. These can be segmented into RBC-models following the classical approach and New-Keynesian models with classical market failures. Along with the former, Finn (1995) allowed energy price shocks to affect capital utilization, a method which has been taken over by several subsequent studies (i.e. Leduc and Sill, 2004; Sánchez, 2011). The idea is that, because energy is dependent on capital utilization and necessary for the usage of physical capital, it enters the production function indirectly. Just as Kim and Loungani (1992), Finn's model assumes perfect competition in the production sector. Along with some other modifications, this results into a model which explains 76 to $89 \%$ of US output volatility. Both, Kim and Loungani, and Finn conclude that shocks in energy prices account for up to $20 \%$ of the aggregate fluctuations in the business cycle.

A further remark which is made by several economists concerns a possible "reallocative" effect of energy shocks (Hamilton, 1983; Loungani, 1986; Mork, 1989). Assuming a multi-sector economy, changes in energy prices can induce individual producers to reallocate other input factors across sectors in a costly manner. Consequently, energy price shocks may have an indirect effect on the macroeconomy through other factors, e.g. labor supply. Shocks in energy prices impact substitution of energy with other input components affecting marginal cost of production. In particular, substitution by capital can influence investment behavior which eventually lead to long run consequences (Amin and Ferdaus, 2015). In our paper, we consider different sources of energy. Hence, reallocation can even take place within the same input factor which is substituted by an alternative.

Specifically talking about oil, Rotemberg and Woodford (1996) have developed a model that is similar to that analyzed by Kim and Loungani (1992), which uses this resource as an independent input factor. However, in contrast to the present paper, the price determination process is still exogenously determined. In their analysis, Rotemberg 
and Woodford find that the predicted aggregate effects of a change in oil prices improves significantly by allowing for a modest degree of imperfect competition. Consequently, in Rotemberg and Woodfords' model, they consider an environment with imperfectly competitive elements rather than a perfectly competitive market. These modifications make it possible to introduce mark-ups in prices. Furthermore, the authors argue that an oil price shock could amplify macroeconomic effects by affecting the costs of production. Since the producer faces changes in costs he is likely to adjust his prices by changing the mark-up of what he is selling. Although considering a model with perfect competition only and ignoring mark-ups, we also find some pass though effects of costs by energy sector as higher costs are added up to the selling price in the present model.

Researchers following the New-Keynesian approach within DSGE models generally assume that shocks are independent of each other. However, several economists have questioned the direct influence of energy shocks to the aggregate output. Leduc and Sill (2004) investigate whether recessionary consequences of an oil-price shock are caused by the shock itself or rather by monetary policy responses to the shock, as it has been argued by Bernanke et al. (1997). They find about $40 \%$ of the output drop which stems from monetary policy intervention. However, these interventions could not be offset by the negative consequences of an oil shock to the aggregate outcome. Sánchez (2011) is one of the first economists who has introduced oil in a model which was based on the Euro area countries. In doing so he implemented oil into an European economic model following the idea by Finn (1995) of linking the required value of oil to the capital utilization rate. By using a standard DSGE model, he demonstrated that gains in oil usage efficiency lead to an alleviation of inflationary and contractionary consequences when an oil shock affects the economy. In addition, he concluded that a higher degree of flexibility in wages can help ease the impact on output, even though this comes at the expense of larger inflationary pressure. These results are confirmed by Jacquinot et al. (2009) within a open country model.

In the present paper, we take over the approach according to the neo-classical approach looking at real variables rather than distinguishing between nominal and real values as it is done in New-Keynesian model. The aim is to concentrate on the origin of business cycles by allowing for several energy sectors rather than restricting different channels though rigidities or imperfect competition. Hereafter, we concentrate on the classical approach to point out the occurrence of business cycles through the interaction of several input factors and their relationships rather than market failures.

All the models described so far are dealing with energy in a very general context. As either the variable itself or the price determining process are exogenously shaped, next to having only one variable with no more other variables, further detailed properties could be neglected by dealing with the remaining dynamics of the model. However, this goes along with less precise description of what causes these exogenous effects. An input 
factor such as oil is constrained by being a finite resource and hence, behaving differently to labor, capital, or even a renewable resource. Literature which investigates optimal depletion of finite resources includes Bohn and Deacon (2000) and Gross et al. (2013). By integrating a separate fossil sector within the models, it allows to analyze its influence on the economy. Bohn and Deacon and Gross et al. even go further by endogenizing the stock of natural resource rather than holding it constant. Firms are allowed to augment existing reserves through exploration which has been previously ignored. However, the price determination process of this resource is still exogenously determined. They find that endogenous reserves have a quite significant effect on the magnitude and persistence of the remaining variables' response to price shocks. In the present paper, we compare both types of stocks but fully endogenizing the price-setting.

$\mathrm{RBC}$ literature which covers resources with different properties namely finite ones and renewable ones is limited. Argentiero et al. (2018) analyze the effects of environmental taxation policy in a model with both resources for China, Europe, and the USA. However, opposite to the present paper, the household sector is much simplified without consumption of energy. Furthermore, the model considers substitution between energy and capital/labor within the production function while we allow for a complementary relationship between energy and capital. While the response of a shock in final good sector's TFP does not distinguish from ours, the results for the dynamics of the remaining shocks do.

Although considering energy as a general and exogenous given variable, Dhawan and Jeske (2008) analyze its role in the household and production sectors. Furthermore, they distinguish between durable and non-durable consumption goods. Assuming a complementary relationship with capital in the production function and durable goods in the household sector they find significant improvements in explaining business cycles. In contrast to Kim and Loungani (1992), disruption in fixed capital investments comes closer to the one observed in the data as the households have an additional channel of adjustments in investments through durable goods. As pointed out by Bernanke et al. (2004), changes in the energy price can induce households to postpone irreversible purchases of durable goods. However, they also find that major impacts causing output fluctuations are still due to productivity shocks. The present paper is based on the work by Dhawan and Jeske by considering multiple margins of investment but endogenizing energy. In doing so, we distinguish between several energy sectors and consequently allowing for different properties in energy resources. As a byproduct, this also allows to implement sectoral productivity to consider disaggregated TFP coming from product and process innovation or further fundamental productivity changes (Caliendo et al., 2017). 


\section{Model}

The model consists of three main sectors: Households, final goods producing firms and energy producing firms. In addition, the latter is divided into three sub-sectors: a general energy sector, a fossil resource sector, and a renewable resource sector. We do not include labor in the production function of the resource sectors as our focus lies on the dynamic change of the capital and reserve stock. In the following, we will describe each sector in more detail.

\subsection{Households}

Households maximize their utility over a semi-CES function by choosing the optimized demand of non-durable and durable consumption goods, demand of energy, supply of labor, and capital which they accumulate through investments. The utility aggregation of households follows:

$$
U_{t}=\vartheta \log \left[C N_{t}^{\gamma}\left(\theta C D_{t-1}^{\zeta}+(1-\theta) E_{t}^{\{\mathrm{H}\}}{ }^{\zeta}\right)^{\frac{1-\gamma}{\zeta}}\right]+(1-\vartheta) \log \left[1-L_{t}\right]
$$

where $\theta \in(0,1)$ indicates the share of durable consumption good and $\vartheta \in(0,1)$ indicates the share of consumption. As $\gamma \in(0,1)$, non-durable goods and a common basket of durable goods and energy are substitutes while $\zeta<0$ implies a complementary relationship between durable goods and energy consumed by households. Empirical observations show that the elasticity of substitution between non-durable and durable goods are close to unity (Greenwood et al., 1995; Ogaki and Reinhart, 1998; Fernandez-Villaverde and Krueger, 2011). Hence, we assume of Cobb-Douglas function between non-durables and the complementary composite basket, similar to Dhawan and Jeske (2008). According to this function, utility increases with consumption of non-durable and durable goods as well as energy but at a decreasing rate. Energy can be considered to be consumed to enhance the consumption of durable goods in a non-perfect substitutable manner. Alternatively, the presence of energy is required to consume durable goods. On the contrary, the supply of labor diminishes households' utility. Theses assumptions are denoted by the partial derivatives:

$$
\begin{aligned}
& U_{C N}^{\prime}>0, U_{C D}^{\prime}>0, U_{E\{\mathrm{H}\}}^{\prime}>0, U_{L}^{\prime}<0 \\
& U_{C N C N}^{\prime \prime}<0, U_{C D C D}^{\prime \prime}<0, U_{E\{\mathrm{H}\}}^{\prime \prime}{ }_{E \mathrm{H}\}}<0, U_{L L}^{\prime}<0
\end{aligned}
$$


Households are restricted by a budget constraint given by:

$$
\begin{array}{r}
C N_{t}+p_{t}^{H} E^{\{\mathrm{H}\}}{ }_{t}+I_{t}^{C D}+I_{t}^{Y}+I_{t}^{F}+I_{t}^{N}=w_{t} L_{t}+r_{t}^{Y} K_{t-1}^{\{\mathrm{Y}\}}+r_{t}^{F} K_{t-1}^{\{\mathrm{F}\}}+r_{t}^{N} K^{\{\mathrm{N}\}}{ }_{t-1} \\
+p_{t}^{S} S_{t}+\pi_{t}^{Y}+\pi_{t}^{N}+\pi_{t}^{F}
\end{array}
$$

Income is gained by the supply of labor in return for wages $w_{t}$ and by undertaking investments $I_{t}$. Households lend capital to the goods production sector and each resource sector which they receive back in the next period with a mark-up in form of interests $r$. We assume that physical investment can only be made to sectors specifically. Hence, once it is invested, it is restricted to specific sectors' capital stock and distinct from other stocks. Furthermore, households can undertake investments in durable goods according to

$$
I_{t}^{C D}=C D_{t}-\left(1-\delta^{C D}\right) C D_{t-1}
$$

which will affect their own utility. As they own all companies and natural resources, their income increases by the flow of all profits and rents from these. Expenditures further exists by consuming non-durable goods from final goods production and spending energy from the energy sector.

\subsection{Final good production}

Non-durable goods which are consumed within the household sector are produced by the final good sector. Here, firms act under perfect competition. Production follows a CES function which is defined by:

$$
Y_{t}=A_{t}^{Y}\left[\eta K_{t-1}^{\{\mathrm{Y}\}^{\nu}}+(1-\eta) E_{t}^{\{\mathrm{Y}\}^{\nu}}\right]^{\frac{\alpha}{\nu}} L_{t}^{1-\alpha}
$$

$A^{Y}$ defines Hicks-neutral technological progress which will be later affected by stochastic shocks. $\eta \in(0,1)$ measure the share of capital with respect to energy and $\nu$ the elasticity of substitution between capital and energy. We assume that $\nu<0$ which leads to a complementary relationship between both input factors. According to that, the efficient usage of capital within the production process require some amount of energy. Moreover, the firm employs labor supplied by households. $\alpha \in(0,1)$ indicates the elasticity of substitution of the capital-energy basket. As the elasticity of substitution between labor and the composite of physical capital and energy is one, final goods are produced with constant returns to scale. This is similar to the aggregated production function used by Kim and Loungani (1992) and Dhawan and Jeske (2008) who also assume a complementary relationship between physical capital and energy. The installation of physical capital 
takes place with a lag, hence in the period before, which is analogous to having fixed investments. The capital stock is accumulated according to the households investment function:

$$
I_{t}^{Y}=K_{t}^{\{\mathrm{Y}\}}-\left(1-\delta^{Y}\right) K_{t-1}^{\{\mathrm{Y}\}}
$$

Final good producing firms face the following profit function:

$$
Y_{t}=r_{t}^{Y} K^{\{\mathrm{Y}\}}{ }_{t-1}^{Y}+w_{t} L_{t}+p_{t}^{E} E^{\{\mathrm{Y}\}}+\pi_{t}^{Y}
$$

By normalizing the price of non-durable goods to one, revenues of firms are equal to $Y$. On the expenditure side, the input factors capital, labor, and energy are payed off with their respective marginal products $w, r^{Y}$, and $p^{E}$.

\subsection{Energy sector}

The energy sector combines both intermediate energy sources (non-renewable and renewable energy) to provide a general energy product to the household sector and the final good sector. As we assume perfect substitution between the input factors, we model the production function as a Cobb-Douglas function.

$$
E_{t}=A_{t}^{E} F_{t}^{\phi} N_{t}^{1-\phi}
$$

where $E$ is the general energy output, $A^{E}$ is Hicks-neutral technological progress, $F$ is the non-renewable energy input, and $N$ is the renewable energy input. $\phi$ determines the elasticity of substitution. The energy sector optimizes its production function with respect to the profit function:

$$
\pi_{t}^{E}=p_{t}^{E} E_{t}-p_{t}^{F} F_{t}-p_{t}^{N} N_{t}
$$

As the energy sector acts under perfect competition, the input factors are payed off with their marginal production, defined by $p^{F}$ and $p^{N} \cdot p^{E}$ is the price for the energy output which is the same for both consumers, households and final good firms.

\subsection{Fossil resource sector}

In the fossil resource sector, the resources are extracted from a finite resource stock and, combined with physical capital, transformed to the intermediate energy good. Here, we follow the idea of Gross et al. (2013) with some minor adjustments. In the present model, the economy is completely closed and consequently capital merely supplied by domestic households. Furthermore, the resource stock is owned by the fossil resource 
sector. Hence, the sector does not face additional occupational costs which have to be paid to some owner. The general production function is defined by:

$$
F_{t}=A_{t}^{F} K_{t-1}^{\{\mathrm{F}\}_{t-1}^{\varphi}} S_{t-\varphi}^{1-\varphi}
$$

where $F$ is the intermediate energy good, $A^{F}$ is the Hicks-neutral technological progress, $K^{\{\mathrm{F}\}}$ is the physical capital stock, and $S$ is the resource stock. $\varphi \in(0,1)$ measures the elasticity of substitution between the input factors in this Cobb-Douglas function. Capital is supplied by the household sector. The accumulation of the physical capital stock $K^{\{\mathrm{F}\}}$ in the production function is standard, following the investment function:

$$
I_{t}^{F}=K_{t}^{\{\mathrm{F}\}}-\left(1-\delta^{F}\right) K_{t-1}^{\{\mathrm{F}\}}
$$

As the resource stock is finite, the fossil resource sector is further affected by the constraint that the resource stock diminishes by the extracted amount of intermediate energy each period.

$$
S_{t}=S_{t-1}-F_{t}+\omega D_{t}
$$

In an extension of the model, the fossil energy sector is able to increase the resource stock by investing in $R \& D$ which is paid off to the households. By assumption, we distinguish between resources and reserves. Reserves have been discovered and can be technically extracted at the current point of time with the available technology. However, resources denote the amount of crude resources that are either not feasible to be extracted due to the costs or due to missing technology. Investment into R\&D allows the transformation of certain share of resources into reserves. After this definition, $S_{t}$ is always the amount of reserves available at that moment. $D$ is the amount of reserve which is replenished through $R \& D$ whereas $\omega \in(0,1)$ is an efficiency parameter. If $\omega=0$, there is no $R \& D$ in the model and consequently no possibility to replenish the resource stock. Expenses in $\mathrm{R} \& \mathrm{D}$ are determined by a non-linear cost function:

$$
C\left(D_{t}, V_{t}\right)=\left(\frac{D_{t}}{V_{t}}\right)^{v}
$$

where $D_{t}$ is the replenished amount of reserves or amount of transformation from resources to reserves. $V_{t}$ is the stock of resources. Although this expenditure function is different, its properties resemble to the model by Gross et al. (2013) as we abstract from the assumption of a finite bound in the level of resources as it is done by Bohn and Deacon (2000). This is fulfilled by assuming that additional reserves can be discovered but at increasing costs. According to this, to transform the last resource unit to a reserve unit 
come with infinite costs. Hence, it will not be mined by the sector. This is satisfied if the following restriction holds:

$$
C_{D_{t}}^{\prime}(\cdot)>0, C_{D_{t}}^{\prime \prime}(\cdot)>0 \quad \text { with } \quad v>0
$$

Similar to the reserve stock, the resource stock is finite and bounded by the constraint:

$$
V_{t}=V_{t-1}-D_{t}
$$

As the fossil resource sector performs under the assumption of perfect competition, its corresponding profit function is given by:

$$
\pi_{t}^{F}=p_{t}^{F} F_{t}-r_{t}^{F} K_{t-1}^{\{\mathrm{F}\}}-C\left(D_{t}, V_{t}\right)
$$

\subsection{Renewable resource sector}

The renewable resource sector generates an intermediate energy good which is completely generated from a capital stock. This follows the assumption that access to renewable natural resources require prior investments in capital. In their paper, Mason et al. (2018) describe this approach to expand capacities of renewable resources. Households, who own this physical capital, invest into and hence, accumulate this stock for capital returns. The harvesting function of this non-finite product follows:

$$
N_{t}=A_{t}^{N} K_{t-1}^{\left\{\mathrm{N}{ }^{\psi}\right.}
$$

$N$ indicates the intermediate energy product, $A^{N}$ the technological progress which is exogenously determined, and $K^{\{\mathrm{N}\}}$ the capital stock of the renewable resource sector. $\psi$ measures the elasticity of substitution of the physical capital input. As $\psi<1$, the harvesting function has decreasing returns to scale. The capital stock is accumulated according to the following function:

$$
I_{t}^{N}=K_{t}^{\{\mathrm{N}\}}-\left(1-\delta^{N}\right) K_{t-1}^{\{\mathrm{N}\}}
$$

The corresponding profit function

$$
\pi_{t}^{N}=p_{t}^{N} N_{t}-r_{t}^{N} K_{t-1}^{\{\mathrm{N}\}}
$$

satisfies the assumption of perfect competition by paying of the input factor capital with the sector's revenue. 


\subsection{Market clearing}

To complete the model, the markets have to be cleared. According to that, the two remaining equations are:

$Y_{t}-p_{t}^{E} E^{\{\mathrm{Y}\}}{ }_{t}+r_{t}^{N} K^{\{\mathrm{N}\}}{ }_{t-1}+r_{t}^{F} K^{\{\mathrm{F}\}}{ }_{t-1}+p_{t}^{S} S_{t}=C N_{t}+p_{t}^{H} E^{\{\mathrm{H}\}}{ }_{t}+I_{t}^{C D}+I_{t}^{Y}+I_{t}^{F}+I_{t}^{N}$

$$
E_{t}=E^{\{\mathrm{H}\}}+E^{\{\mathrm{Y}\}}{ }_{t}
$$

which determine the general market clearing as well as the clearing of energy. The market value is calculated by using the expenditure approach.

Total factor productivity distinguishes in all three producing sectors. Their laws of motion are described by the following functions:

$$
\begin{aligned}
& \widehat{A_{t}^{Y}}=\rho_{Y} \widehat{A_{t-1}^{Y}}+\sigma_{Y} \\
& \widehat{A_{t}^{E}}=\rho_{E} \widehat{A_{t-1}^{E}}+\sigma_{E} \\
& \widehat{A_{t}^{F}}=\rho_{F} \widehat{A_{t-1}^{F}}+\sigma_{F} \\
& \widehat{A_{t}^{N}}=\rho_{N} \widehat{A_{t-1}^{N}}+\sigma_{N}
\end{aligned}
$$

They follow an $\mathrm{AR}(1)$ process with zero mean and uncorrelated variance $\sigma_{i}, i \in(Y, E, F, N)$. The parameter $\rho_{i}, i \in(Y, E, F, N)$ measures the persistence of TFP.

\section{Competitive Equilibrium}

After setting up the model, each actor maximizes its functions to optimize its decisionmaking. In the following, we solve the model for each sector successively. The equations are derived in detail in appendix D. The representative household decides about its demand for consumption of non-durable goods, durable goods, and energy as well as its 
supply of labor to maximize expected lifetime utility. The household faces the following optimization problem:

$$
\begin{aligned}
\max _{C N, C D, E\{\mathrm{H}\}, L, K_{0}\{\mathrm{Y}\}, K^{\{\mathrm{F}\}}, K\{\mathrm{~N}\}} \sum_{0}^{\infty} \beta \mathbb{E} & \left\{\vartheta \log \left[C N_{t}^{\gamma}\left(\theta C D_{t-1}^{\zeta}+(1-\theta) E^{\{\mathrm{H}\}}{ }_{t}^{\zeta}\right)^{\frac{1-\gamma}{\zeta}}\right]+(1-\vartheta) \log \left[1-L_{t}\right]\right\} \\
& +\lambda_{t}^{H}\left\{C N_{t}+p_{t}^{H} E^{\{\mathrm{H}\}}{ }_{t}+I_{t}^{C D}+I_{t}^{Y}+I_{t}^{F}+I_{t}^{N}-w_{t} L_{t}-r_{t}^{Y} K^{\{\mathrm{Y}\}}{ }_{t-1}\right. \\
& \left.-r_{t}^{F} K^{\{\mathrm{F}\}}{ }_{t-1}-r_{t}^{N} K^{\{\mathrm{N}\}}{ }_{t-1}-p_{t}^{S} S_{t}-\pi_{t}^{Y}-\pi_{t}^{N}-\pi_{t}^{F}\right\}
\end{aligned}
$$

where $\beta$ serves as a time preference parameter to discount future utility streams. The associated FOCs with respect to $C N, C D, E^{\{\mathrm{H}\}}, L, K^{\{\mathrm{Y}\}}, K^{\{\mathrm{F}\}}$, and $K^{\{\mathrm{N}\}}$ are summarized below:

$$
\begin{gathered}
1=\mathbb{E}\left\{\beta \frac{1-\gamma}{\gamma} \theta \frac{C D_{t}^{\zeta-1} C N_{t}}{\theta C D_{t}^{\zeta}+(1-\theta) E_{t+1}^{\{\mathrm{H}\}} \zeta}\right\}+\mathbb{E}\left\{\beta \frac{C N_{t}}{C N_{t+1}}\left(1-\delta^{C D}\right)\right\} \\
p_{t}^{E}=\frac{(1-\gamma)(1-\theta)}{\gamma} \frac{C N_{t} E_{t}^{\{\mathrm{H}\}_{t}^{\zeta-1}}}{\left(\theta C D_{t}^{\zeta}+(1-\theta) E^{\{\mathrm{H}\}}{ }_{t}^{\zeta}\right)} \\
w_{t}=\frac{C N_{t}}{1-L_{t}} \frac{1-\gamma}{\gamma \vartheta} \\
1=\mathbb{E}\left\{\beta \frac{C N_{t}}{C N_{t+1}}\left(1+r_{t+1}^{i}-\delta^{i}\right)\right\} \quad \text { for: } i=Y, F, N
\end{gathered}
$$

The trade off between non-durable consumption goods and the composite basket including durables and energy is described in eq. (26) while eq. (27) determines the demand for energy, given its price. Eq. 28, shows the intra temporal optimality condition of labor supply in relation with consumption of nun-durables, given the wage. Disutility from labor due to an increasing in working hours is compensated by a decrease of consumption at constant wages. Eq. 29 describes the Euler equations which imply that current marginal utility of consumption on nun-durable goods is equal to the discounted utility of future consumption.

The final good sector maximizes current profits with respect to its input factors which are paid off according to their respective marginal productivities:

$$
r_{t}^{Y}=A_{t}^{Y} \alpha \eta\left[\eta K_{t-1}^{\{\mathrm{Y}\}^{\nu}}+(1-\eta) E_{t}^{\{\mathrm{Y}\}^{\nu}}\right]^{\frac{\alpha}{\nu}-1} L^{1-\alpha} K_{t-1}^{\{\mathrm{Y}\}^{\nu-1}}
$$




$$
\begin{gathered}
p_{t}^{E}=A_{t}^{Y} \alpha \eta\left[\eta K_{t-1}^{\{\mathrm{Y}\}^{\nu}}+(1-\eta) E_{t}^{\{\mathrm{Y}\}^{\nu}}\right]^{\frac{\alpha}{\nu}-1} L^{1-\alpha} E_{t}^{\{\mathrm{Y}\}^{\nu-1}} \\
w_{t}=A_{t}^{Y}(1-\alpha)\left[\eta K_{t-1}^{\{\mathrm{Y}\}^{\nu}}+(1-\eta) E_{t}^{\{\mathrm{Y}\}^{\nu}}\right]^{\frac{\alpha}{\nu}} L^{-\alpha}
\end{gathered}
$$

The associated demand functions of the input factors of the energy sector, based on the profit function under perfect competition, given $p^{F}$ and $p^{N}$ are:

$$
\begin{gathered}
p_{t}^{F}=\phi p_{t}^{E} A_{t}^{E} F_{t}^{\phi-1} N^{1-\phi} \\
p_{t}^{R}=(1-\phi) p_{t}^{E} A_{t}^{E} F_{t}^{\phi} N_{t}^{-\phi}
\end{gathered}
$$

The fossil resource sector faces a finite resource stock constraint and at given conditions also with a finite reserve stock. Thus, the firm's decision problem depends on choosing the optimal demand for raw resources, physical capital, and optimal setting of R\&D strategy. The subsequent dynamic problem is given by:

$$
\begin{aligned}
\max _{K, S, D} & \pi^{F}\left(K^{\{\mathrm{F}\}}, S_{t}, D_{t}, V_{t}\right)=p_{t}^{F} F_{t}-r_{t}^{F} K^{\{\mathrm{F}\}}{ }_{t-1}-C\left(D_{t}, V_{t}\right) \\
& +\lambda_{t}^{F S}\left\{S_{t-1}-F_{t}+\omega D_{t}-S_{t}\right\}+\lambda_{t}^{F V}\left\{V_{t-1}-D_{t}-V_{t}\right\}
\end{aligned}
$$

The corresponding demand functions read as follows:

$$
\begin{gathered}
p_{t}^{F}=\beta \mathbb{E}\left\{(1-\varphi) p_{t}^{F} \frac{F_{t+1}}{S_{t}}+p_{t+1}^{F}-r_{t+1}^{F} \frac{K_{t}}{F_{t+1} \varphi}\right\}+r_{t}^{F} \frac{K_{t-1}}{F_{t} \varphi} \\
D_{t}^{v-1} V_{t}^{-v}=\beta \mathbb{E}\left\{D_{t+1}^{v-1} V_{t+1}^{-v}-D_{t+1}^{v} V_{t+1}^{-v-1}\right\}
\end{gathered}
$$

As $\beta \in(0,1)$, eq. 36 shows that the inflation rate of the price for intermediate fossil energy is positive. Note, that this function is similar to the Hotelling rule (Hotelling, 1931) saying that the rate of price increase equals, among others, the social discount rate. Eq. 37 denote that the sector equation its marginal costs of R\&D for exploration to the marginal revenue it earns from selling the intermediate fossil energy product.

The renewable energy sector maximizes current-period profit under perfect competition. Consequently, the first order condition for the only input factor physical capital is as follows:

$$
r_{t}^{N}=\psi p_{t}^{N} A_{t}^{N} K_{t-1}^{\{\mathrm{N}\}}
$$


describing the price of physical capital, invested in the renewable energy sector. It increases with a higher scarcity of capital stock and a higher profit of the renewable sector though higher productivity or selling prices.

\section{Parameter calibration/estimation}

In a next step, parameters have to be determined to be able to proceed with the numerical as well as the dynamic analysis of the model. We estimate these values in the course of this paper based on calibrated values which have to be determined in the first instance using real long-term data. Subsequently, we define the distributions, hence the kernel and the variance, on which the posterior parameters are estimated. The estimation is based on Bayesian techniques and is carried out with data about the German economy which is discussed more detailed below.

\subsection{Data and estimation methodology}

In order to estimate the parameters to apply the model to Germany, we use data for the period 1991 (earliest year in which sufficient detailed data about energy market is available) to 2014. Two macroeconomic variables and three variables describing the development in the energy sectors are considered. In particular, we look at: (i) economic output, (ii) consumption of durable goods, (iii) total energy consumption, (iv) fossil energy consumption, and (v) renewable energy consumption.

As aggregated economic output, we take the output approach of gross domestic product (GDP) from OECD (2012) at constant prices based on the reference year 2010 (Code: B1_GA). Durable goods consumption is also taken from OECD at constant prices (Code: P311B). The remaining three energy time series are taken from Eurostat $(2017,2018)$. Total energy consumption is defined as gross inland consumption of all energy products (Code: nrg_110a_1). Fossil energy includes the consumption of gas, nuclear energy, solid fuels, and total petrol (Code: nrg_100a_1). All remaining consumption of energy is referred to renewable energy products. All energy products are measures in terajoule to have a common unit which allows a better comparison and relation. As records for energy consumption and production as well as consumption of durable goods are not sufficiently recorded in short term units of time, the data is used on annual frequency. To avoid stochastic singularity, the number of time series also determines the amount of exoge- 
nous shocks which have to be at least applied to the model. To make the data applicable to our model, the following measurement equation holds:

$$
\left[\begin{array}{c}
\Delta \ln G D P_{t} \\
\Delta \ln C N_{t} \\
\Delta \ln C D_{t} \\
\Delta \ln E_{t} \\
\Delta \ln F_{t} \\
\Delta \ln N_{t}
\end{array}\right]=\left[\begin{array}{c}
\overline{G D P} \\
\overline{C N} \\
\overline{C D} \\
\bar{E} \\
\bar{F} \\
\bar{N}
\end{array}\right]+\left[\begin{array}{c}
G D P_{t}-G D P_{t-1} \\
C N_{t}-C N_{t-1} \\
C D_{t}-C D_{t-1} \\
E_{t}-E_{t-1} \\
F_{t}-F_{t-1} \\
N_{t}-N_{t-1}
\end{array}\right]
$$

The first vector includes the log difference from the trend path while the second vector describes the trend growth rate for each variable respectively. The trends are identified by applying a HP-filter of each time series respectively (see appendix F) ${ }^{1}$. In the third vector, the variables are included as first difference from the previous period. Overall, this equation mirrors the relationship between empirical values from the data on the left hand side and theoretical values from the model on the right hand side. As the model includes stationary data only, we pursue to calibrate and estimate the model as good as to fit the theoretical values close to their empirical counterparts.

\subsection{Calibration}

Independently of whether or not the model should be analyzed with calibrated parameters or estimated values from priors, we have to critically identify both of them based on the given model. Here, the parameters can be split up into two groups. Structural parameters which determine the dynamics of the model and steady state values such as average ratios which describe the general state of the economy. We follow three approaches to match an annual time horizon reflecting most of the features of the German economy. Some parameters are calibrated (i) using empirical data to fit the model with real data, some parameters are (ii) taken from existing literature, mainly in the field of RBC models dealing with energy in general or specific sources of energy production while some other parameter are (iii) calculated from the steady state of the model. Altogether, there are 24 structural parameters which can be distinguished by 16 structural parameters and 8 shock related parameters. Structural parameters are categorized as numerical factors defining the system of sectors such as utility function or production function. As prices, in particular those of resources, are completely endogenously determined, shocks affect technological progress of each production sector only. They define how TFPs behave over time. Table 5.2 to 5.2 give an overview about the definition of parameters as well as their prior values, sorted according to their respective category.

\footnotetext{
${ }^{1}$ For yearly data we use a HP parameter of $\lambda=100$
} 
A number of parameter are initially taken as fixed. We set $\alpha=0.38$, leading to a labor income share in good production output of $62 \%$. The goes along with Schmidt and Zimmermann (2005) who determined this value equal to the proportion of labor income on average for Germany. The time discount factor $\beta=0.99$ and the elasticity of substitution of the durable good/energy consumption bundle and non-durable goods in the utility function amounts for $\zeta=-2.8748$ according to Dhawan and Jeske (2008). Similarly, the elasticity of substitution within the final good production function is set to $\nu=-0.7$, following Kim and Loungani (1992). All these parameters have to be carefully chosen as they cannot be altered by remaining variables later on.

Moreover, the parameters $\zeta$ and $\theta$ in the utility function and $\nu$ and $\eta$ in the final good production function cannot be simultaneously calibrated due to an identification problem. Hence, either of those must be predetermined, in our case the elasticities in these functions. Subsequently, the particular share parameters are calculated to match empirical data. The weight of overall consumption within the utility function is set to $\vartheta=0.341$ which is determined by the steady state of the wage equation and labor supply equation. The depreciation rate of durable goods is taken from Dhawan and Jeske (2008) with the assumption that the behavior of U.S. households does not distinguish from German consumers significantly. Accordingly, $\delta^{C D}$ is set to 0.0683. Regarding the motion of the capital stock, used in the final good sector, its depreciation rate is calculated from the time preference rate and the steady state interest rate while the latter is calculated from the log run first order condition of the production function.

The depreciation rate of fossil capital is determined by the long run capital/output ratio and investments into the former. Under consideration of its different weights, the combined rates resemble the general depreciation rate of the German economy. The elasticity of substitution of intermediate fossil energy is set to $\phi=0.88$ following Argentiero et al. (2018). It approximately reflects the average relation between non-renewable energy with respect to renewable energy. This comes close the the average proportion in Germany for the observed time period. The elasticities of physical capital in the intermediate fossil energy generation function and the intermediate renewable energy generation function are set to $\varphi=0.62$ according to Gross et al. (2013) and $\psi=0.3$ according to Argentiero et al. (2018) respectively. The remaining structural parameters are determined from the given parameters and empirical findings. A more detailed derivation of the calibrated parameters can be found in the appendix E.

Table 1: Structural Parameter Values

\begin{tabular}{ccc}
\hline Parameter & Value & Description \\
\hline$\beta$ & 0.990 & discount factor \\
$\vartheta$ & 0.341 & share of consumption in utility \\
$\gamma$ & 0.782 & elas. of substitution of consumption
\end{tabular}


Table 1 - Continued

\begin{tabular}{ccc}
\hline Parameter & Value & Description \\
\hline$\zeta$ & -2.875 & elas. of substitution between $C D$ and $E^{H}$ \\
$\theta$ & 0.848 & share of durable consumption good \\
$\alpha$ & 0.360 & final output elas. of VA \\
$\eta$ & 0.998 & share of capital \\
$\nu$ & -0.700 & elas. of substitution between $K^{Y}$ and $E^{Y}$ \\
$\phi$ & 0.880 & fossil resource share \\
$\varphi$ & 0.490 & fossil resource share \\
$\omega$ & 1.000 & exploration parameter \\
$v$ & 2.000 & parameter of exploration cost function \\
$\psi$ & 0.310 & renewable asset share \\
$\delta_{C} D$ & 0.068 & depreciation rate $C D$ \\
$\delta_{Y}$ & 0.017 & depreciation rate $K^{Y}$ \\
$\delta_{F}$ & 0.045 & depreciation rate $K^{F}$ \\
$\delta_{N}$ & 0.045 & depreciation rate $K^{N}$ \\
\hline
\end{tabular}

The shock related parameters, in particular the coefficients describing the autoregressive process of total factor productivity in each production function, are assumed to be uniformly equal to 0.85 . This reflects a modest reduction of the direct impulse of stochastic shocks and follows real business cycle literature.

Table 2: Shock related Parameter Values

\begin{tabular}{ccc}
\hline Parameter & Value & Description \\
\hline$\rho_{A_{Y}}$ & 0.850 & persistence technology shock of $A^{Y}$ \\
$\rho_{A_{E}}$ & 0.850 & persistence technology shock of $A^{E}$ \\
$\rho_{A_{F}}$ & 0.850 & persistence technology shock of $A^{F}$ \\
$\rho_{A_{N}}$ & 0.850 & persistence technology shock of $A^{N}$ \\
$\rho_{T}$ & 0.780 & persistence consumer taste shock of $C N$ \\
$\rho_{S}$ & 0.000 & persistence reserve shock \\
$\sigma_{A_{Y}}$ & 0.010 & volatility shock in $A^{Y}$ \\
$\sigma_{A_{E}}$ & 0.010 & volatility shock in $A^{E}$ \\
$\sigma_{A_{F}}$ & 0.010 & volatility shock in $A^{F}$ \\
$\sigma_{A_{N}}$ & 0.010 & volatility shock in $A^{N}$ \\
$\sigma_{T}$ & 0.010 & volatility shock in $T$ \\
$\sigma_{S}$ & 0.010 & volatility shock in $S$ \\
\hline
\end{tabular}

For steady state values, we calibrate parameters which are consistent with long run historical averages from data. Only for labor supply, we set its long-run steady state 
value to $\bar{L}=0.3$ as it is also standard in the literature. Although this goes along with Dhawan and Jeske (2008), it hold very close to its German equivalent (see Hristov, 2016). However, as there are not good measures available for some data, modification of certain values is requested. As such, the depreciation rate of the stock of physical capital in the renewable energy sector, belonging to the group of structural parameters, is taken over from the its appropriate value in the fossil resource sector. Furthermore, since the model does not distinguish between several forms of finite resources, we have to combine its various expression in one term which are calculated considering their respective heating values (see appendix E for a detailed discussion). The ratio between extraction of fossil resources and its stock is calculated from data retrieved from the Federal Institute for Geosciences and Natural Resources (BGR, 2016). For the German economy, the $\bar{F} / \bar{S}$ ratio is set to 0.12875 .

Table 3: Parameter Values

\begin{tabular}{|c|c|c|c|c|c|}
\hline Parameter & Value & Description & Parameter & Value & Description \\
\hline$L_{\mathrm{SS}}$ & 0.300 & SS of labor & $\frac{\overline{\bar{R}}^{F} * \overline{K^{\{F\}}}}{\overline{\bar{Y}}}$ & 0.001 & SS $\frac{R^{F} * K^{F}}{Y}$ \\
\hline $\bar{R}^{Y}$ & 0.027 & $\mathrm{SS}$ of interest rate of $K^{Y}$ & $\frac{\bar{R}^{N} * \frac{Y}{\bar{Y}}\{\mathrm{~N}\}}{\bar{Y}}$ & 0.004 & SS $\frac{R^{N} * K^{N}}{Y}$ \\
\hline $\bar{R}^{N}$ & 0.055 & SS of interest rate of $K^{N}$ & $\kappa_{R^{F}}$ & 0.055 & $\mathrm{SS} R^{F}$ \\
\hline$\frac{\overline{C N}}{\overline{C D}}$ & 0.384 & SS $\frac{\overline{C N}}{\overline{C D}}$ & $\frac{\underline{F}}{\bar{S}}$ & 0.129 & SS $\overline{\bar{F}}$ \\
\hline$\frac{\bar{K}}{\bar{Y}}$ & 59.245 & $\mathrm{SS} \frac{K^{Y}}{I^{Y}}$ & $\frac{\overline{K^{\{F\}}}}{\bar{I}^{F}}$ & 22.083 & $\mathrm{SS} \frac{K^{F}}{I^{F}}$ \\
\hline$\frac{\frac{L^{N}}{\bar{J}^{N}}}{4}$ & 22.083 & $\mathrm{SS} \frac{K^{N}}{I^{N}}$ & $\frac{\bar{Y}}{G D P}$ & $\mathrm{NaN}$ & SS $\frac{Y}{G D P}$ \\
\hline$\frac{\frac{1}{E} Y}{\bar{E}}$ & 0.475 & SS $\frac{E^{Y}}{E}$ & $\bar{p}^{F}$ & 0.027 & $\mathrm{SS} \bar{p}^{F}$ \\
\hline$\frac{\frac{E^{H}}{\bar{E}}}{\bar{E}}$ & 0.525 & SS $\frac{E^{H}}{E}$ & $\bar{I}^{Y}$ & 11.838 & $\operatorname{SS} \frac{I^{Y}}{Y}$ \\
\hline$\frac{\frac{L D}{C D}}{\bar{I}^{m C D}}$ & 14.662 & SS $\frac{C D}{I^{C} D}$ & $\bar{I}^{Y}$ & 1.571 & $\operatorname{SS} \frac{I^{Y}}{Y}$ \\
\hline $\bar{I}^{Y}$ & 0.200 & $\operatorname{SS} \frac{I^{Y}}{Y}$ & $\bar{I}^{Y}$ & 0.045 & $\operatorname{SS} \frac{I^{Y}}{Y}$ \\
\hline $\bar{I}^{N}$ & 0.003 & SS $\frac{I^{N}}{Y}$ & $\bar{I}^{Y}$ & 0.041 & $\operatorname{SS} \frac{I^{Y}}{Y}$ \\
\hline$\frac{\overline{C N}}{\bar{Y}}$ & $\mathrm{NaN}$ & $\mathrm{SS} \frac{C N}{Y}$ & $\frac{\bar{D}}{\bar{V}}$ & 0.025 & SS $\frac{D}{V}$ \\
\hline$\frac{\bar{I}^{C D}}{\bar{Y}}$ & 0.107 & $\operatorname{SS} \frac{I^{C} D}{Y}$ & $\frac{\frac{V}{C}}{G D P}$ & 0.001 & $\mathrm{SS} \frac{C}{G D P}$ \\
\hline$\frac{\bar{I}^{F}}{\bar{Y}}$ & 0.001 & $\operatorname{SS} \frac{I^{F}}{Y}$ & $\frac{\bar{D}}{\bar{S}}$ & 0.029 & SS $\frac{D}{S}$ \\
\hline
\end{tabular}

\subsection{Estimation Methodology}

To determine the model by specifying the parameters, we use the concept of Bayesian estimation which gives us a few advantages. It incorporates the derivation of the modes by combining log-likelihood maximization with the confrontation of the model with data through priors. These priors work as weights in the maximization process to avoid strange peak of the log-likelihood function. Otherwise, as pointed out by Griffoli (2007), this can lead to a frequent property of DSGE models that likelihood maximization can lead to 
illogical or foolish outcomes that contradict with observations in data which is caused by their stylized and misspecified nature. Furthermore, opposed to GMM, Bayesian estimation fits the complete model and not only particular equilibria. However, this also goes along with an adequate definition of the model to avoid misspecification of all estimation results. Moreover, Bayesian techniques can cope with a lack of identification of parameters and is therefore also more robust to outliers in the data. Assuming a peak of likelihood function using false insufficient priors, it will lead to a low probability of the the posterior results. Subsequent to identifying the likelihood function to estimate the modes of the parameters, we perform a MCMC applying the Metropolis Hansting algorithm to obtain the full posterior distribution of the values. In addition, this also acts as a diagnostic tool to check the robustness of the results to build up confidence in our estimations. The comparison of the prior and posterior distributions is shown in appendix B.

\subsection{Prior parameters}

Subsequently, we determine the probability distributions of all parameters which will be estimated. These densities reflect beliefs about the parameter values and should be carefully chosen. The previously determined calibration results are taken as means to avoid diffuse results as they mainly base on data. Standard deviations and prior distributions are listed up in the third and forth column of table 4 and 5 .

For the capital-energy bundle elasticity of substitution in the final good production function as well as the major elasticities in the remaining production functions $\{\alpha, \phi, \varphi, \psi\}$, we assume a variance of $\{0.05,0.1,0.1,0.1\}$ and a beta distribution to constrained the parameter between zero and one. The elasticity parameters within the durable good - energy bundle and capital-energy bundle $\{\zeta, \nu\}$ are distributed according to a normal probability distributed function with a variance of 0.5 and 0.2 respectively as they do not only contain natural numbers but all real numbers. The share parameters in both CES functions, the utility function and final good production function $\{\theta, \eta\}$, are determined by $\zeta$ and $\nu$ (see appendix E). The depreciation rates $\left\{\delta_{C D}, \delta_{Y}, \delta_{F}, \delta_{N}\right\}$ follow a beta distribution with a standard deviation of 0.05 final good productive capital, fossil and renewable capital deposits and 0.1 for durable good stock.

For shock related parameters, determining the development of technological progress in the production functions, we have beta distributions limiting the range to positive values only. Furthermore, this guarantees a stable development to avoid unit roots. The standard deviations of white noise in these autoregressive functions, which acts as the shock components at the same time, follow an inverse-gamma distribution with a mean of 0.01 and an infinite standard deviation. 


\subsection{Posterior parameters}

All parameters seem to be well identified which is confirmed by identification tests within Dynare $^{2}$. The resulting values from Bayesian estimation performance are summarized in the last four columns of tables 4-5, distinguishing between the posterior mode, the posterior standard deviation, and the $90 \%$ confidence interval for the model parameters. In addition, a graphical representation of the prior and posterior densities is included in appendix B.

The elasticity of substitution within the durable good - energy bundle is -2.844 which comes close to its prior value. Similar, the posterior of elasticity of substitution of capital - energy amounts to -0.699 which also complies with its prior. The present outcomes verify the assumption of complementary relationship between energy and durable goods or physical capital in the utility or production function, even by considering the $90 \%$ confidence interval. The posteriors of the remaining structural parameters lie in the range of the prior values which have been originally calibrated from the data. Furthermore, they roughly correspond to the findings of the literature. The elasticity of substitution of the capital-energy bundle $\alpha$ is only slightly lower than its prior. Argentiero et al. (2018) estimate a mean of 0.395 but assume a substitutable relationship between energy and capital while Dhawan and Jeske (2008) set an elasticity of 0.36, assuming the same structure as in the present paper. Posterior estimation values of depreciation of physical capital in all sectors including durable goods are almost identical to their prior estimation values. This can be explained as they are not well identified by the data, in particular through the assumption of equal values for fossil and renewable physical capital. Overall, this is negligible due to a lower share in production function.

Looking at the mean of the shock related parameters describing the autoregressive process, its posterior values are close to the priors for the energy sector, the fossil resource sector and the renewable resource sector as well as consumer taste. Stochastic technological change in the final output sector vanishes at a higher speed however together with a higher standard deviation. The variance describing the stochastic component is close to the prior. Only for the technological process in the renewable resource sector and the process of the finite resource stock, they are significantly more volatile with standard deviation of $5.3 \%$ and $2.5 \%$. But the latter is assumed to influence the stock with no autoregressive process, consequently, it only has a one time effect.

In the model allowing for replenishment of the reserve stock, the posterior structural parameters are in accordance with the results from the basic model. In particular, complementary relationship through $\zeta$ and $\nu$ are again confirmed. The estimated value of

\footnotetext{
${ }^{2}$ In fact, we perform two independent tests based on the prior parameters. One is checking for identification according to Ratto and Iskrev (2011), the other one is a sensitivity test which looks at unique solutions, indeterminacy, and explosive solutions.
} 
the additional parameter $v$, measuring the exponent of the exploration cost function, is higher that the prior estimated value which slightly increases the cost of R\&D.

Table 4: Results from Metropolis-Hastings (parameters)

\begin{tabular}{lccccccccc}
\hline & \multicolumn{3}{c}{ Prior } & & \multicolumn{4}{c}{ Posterior } \\
\cline { 9 - 10 } \cline { 7 - 8 } & Dist. & Mean & Stdev. & & Mean & Stdev. & HPD inf & HPD sup \\
\hline$\rho_{A_{Y}}$ & beta & 0.850 & 0.1000 & & 0.938 & 0.0494 & 0.8877 & 0.9927 \\
$\rho_{A_{E}}$ & beta & 0.850 & 0.1000 & & 0.778 & 0.0980 & 0.6264 & 0.9421 \\
$\rho_{A_{F}}$ & beta & 0.850 & 0.1000 & & 0.848 & 0.1012 & 0.7046 & 0.9943 \\
$\rho_{A_{N}}$ & beta & 0.850 & 0.1000 & & 0.793 & 0.0921 & 0.6461 & 0.9435 \\
$\rho_{T}$ & beta & 0.750 & 0.1000 & & 0.797 & 0.0915 & 0.6589 & 0.9451 \\
$r h o_{-} T D$ & beta & 0.750 & 0.1000 & & 0.598 & 0.1022 & 0.4343 & 0.7715 \\
$\zeta$ & norm & -2.875 & 0.5000 & & -2.896 & 0.4938 & -3.7094 & -2.0964 \\
$\nu$ & norm & -0.700 & 0.2000 & & -0.760 & 0.1921 & -1.0775 & -0.4491 \\
$\alpha$ & beta & 0.380 & 0.0500 & & 0.393 & 0.0499 & 0.3118 & 0.4754 \\
$\varphi$ & beta & 0.490 & 0.1000 & & 0.463 & 0.1005 & 0.2991 & 0.6280 \\
$\psi$ & beta & 0.310 & 0.1000 & & 0.302 & 0.0986 & 0.1403 & 0.4606 \\
$\phi$ & beta & 0.800 & 0.0100 & & 0.813 & 0.0099 & 0.7967 & 0.8290 \\
$\delta_{C} D$ & beta & 0.068 & 0.0100 & & 0.065 & 0.0097 & 0.0489 & 0.0805 \\
$\delta_{F}$ & beta & 0.045 & 0.0100 & & 0.045 & 0.0098 & 0.0288 & 0.0605 \\
$\delta_{Y}$ & beta & 0.017 & 0.0100 & & 0.012 & 0.0064 & 0.0018 & 0.0213 \\
$\delta_{N}$ & beta & 0.045 & 0.0100 & & 0.045 & 0.0102 & 0.0283 & 0.0612 \\
\hline
\end{tabular}

Table 5: Results from Metropolis-Hastings (standard deviation of structural shocks)

\begin{tabular}{|c|c|c|c|c|c|c|c|}
\hline & \multicolumn{3}{|c|}{ Prior } & \multicolumn{4}{|c|}{ Posterior } \\
\hline & Dist. & Mean & Stdev. & Mean & Stdev. & HPD inf & HPD sup \\
\hline$u_{-} A_{-} y$ & invg & 0.010 & Inf & 0.012 & 0.0017 & 0.0092 & 0.0145 \\
\hline$u_{-} A_{-} e$ & invg & 0.010 & Inf & 0.009 & 0.0013 & 0.0066 & 0.0109 \\
\hline$u_{-} A_{-} f$ & invg & 0.010 & Inf & 0.019 & 0.0026 & 0.0147 & 0.0231 \\
\hline$u \_A \_n$ & invg & 0.010 & Inf & 0.041 & 0.0057 & 0.0314 & 0.0495 \\
\hline$u_{-} T$ & invg & 0.010 & Inf & 0.040 & 0.0152 & 0.0161 & 0.0622 \\
\hline$u \_T D$ & invg & 0.010 & Inf & 0.031 & 0.0044 & 0.0240 & 0.0380 \\
\hline$u_{-} S$ & invg & 0.010 & Inf & 0.007 & 0.0041 & 0.0023 & 0.0124 \\
\hline
\end{tabular}




\section{$6 \quad$ Numerical Results}

In the following, we compare the percentage standard deviation (2nd moment) of selected variables from the model with their respective value in German data using a HP-filter. To do that, we can test how accurate the models with endogenous energy producing sectors can fit the business cycle of Germany. We simulated both models, without and with extraction, over 1000 periods, taking the estimated posterior parameters, to received the moments of simulated variables. In addition, we present the results of the simulations by allowing for one shock only respectively for the baseline model without extraction.

Table 6: Percentage standard deviation

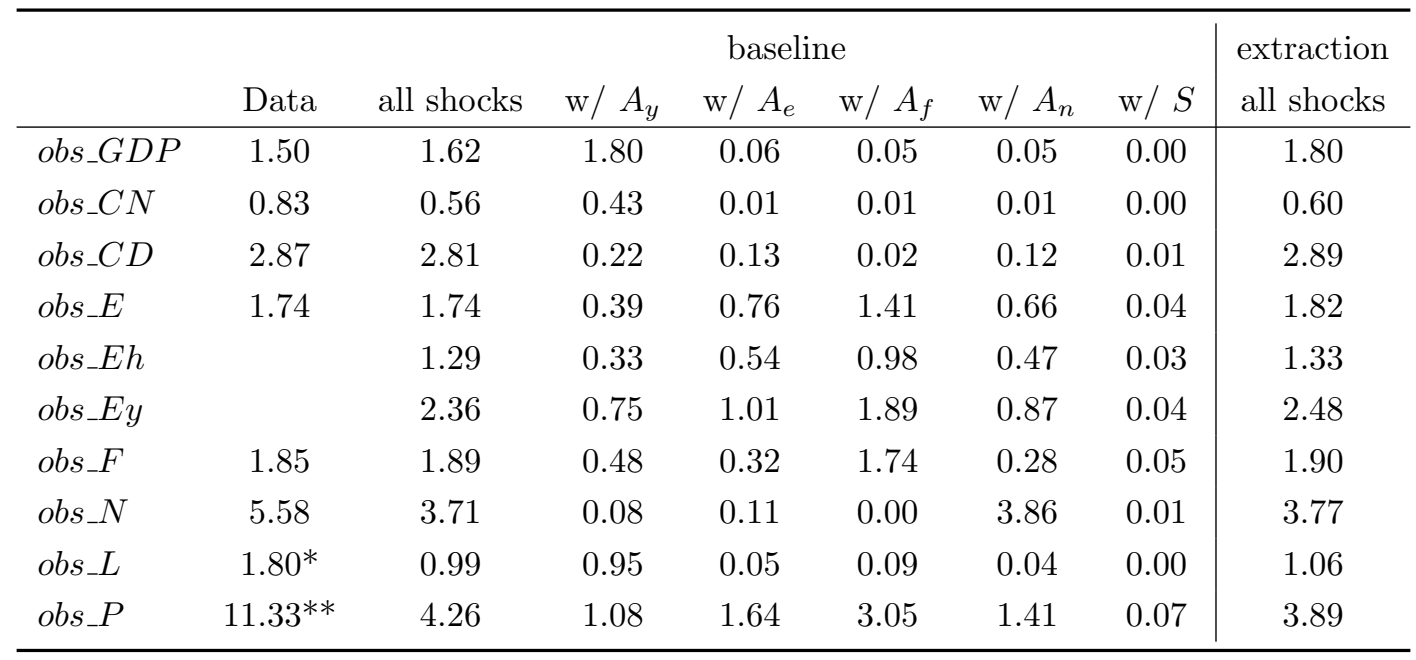

In the baseline model considering an economy without extraction which is affected by all shocks, output volatility is close to that in the data. Comparing that result with those from the models being affected by a single shock only, we can identify TFP as the main source of generating output fluctuation. The model can account for about $67 \%$ of consumption volatility of non-durable goods while it is only slightly below the empirical target for durable goods. Although Dhawan and Jeske (2008) calibrated their model for the U.S. economy whose data deviates slightly from the German data, the present endogenized model is able to replicating business cycles more accurate. Volatility of total energy is well-matched by the model. However, most of the fluctuation are generated by TFP in fossil energy production accounting for more than $80 \%$. Models with shocks in the total energy sector or renewable energy sector can explain $48 \%$ and $40 \%$ respectively while TFP shocks in the final good sector only generate solely $22 \%$. The lower share of renewable energy resources in the total energy mix is the main reason for its lower rate of explanation. In sum, total output fluctuation are mainly driven by TFP shocks in the final good sector in spite of energy endogenously generated. However, the presence of the 
latter seems to improve the explanation of volatility in durable goods which is by far closer to its data compared to Dhawan and Jeske (2008). In a model with an exogenous energy price process calibrated for Germany, Schmidt and Zimmermann (2005) can only account for $8 \%$ of output volatility for a time period 1987-2002. In the present model, volatility is only slightly above the target value, exceeding it by $8 \%$. Extending the baseline model by allowing for a separate extraction of fossil resources, implements a further source of fluctuation to the model. The respective simulated percentage standard deviation in the last column of table 6 confirms that as the volatility in all variables is slightly higher. In particular for both consumption goods, the second moments get closer to the data compared to the baseline model.

\section{Dynamic Results}

In this section, we examine the impulse response function to changes in the productivity processes within the production functions $A_{y}, A_{e}, A_{f}$, and $A_{n}$ as well as a shock in the stock of fossil reserves $S$. Hence, we neglect the effect of a shock in consumer taste as it looks similar as a shock in TFP for the final good sector. The dynamic results are based on the calibrated and estimated values, hence, the shocks correspond to the individual standard deviations of positive shocks $u_{Y}, u_{E}, u_{F}, u_{N}$, and $u_{S}$. In addition, the application of Bayesian estimation allows for sketching the confidence band into the IRFs (gray area). The graphs aim to explain two questions: Firstly, how do the endogenous variables respond to shocks in productivity levels/stock of reserves. Secondly, to what extend do the responses differ allowing for replenishment of the fossil reserve stock. For better visibility, we included the dynamics of both models in the same graphs.

\subsection{Shock to TFP in the final good sector}

Figures 1 - 3 show the IRFs after a positive shock in total factor productivity in the final good sector. As expected, there is a positive effect on the sector's output as the same unit of all input factors becomes more productive, other things equal. At the same time, this also leads to an increase in GDP. On the consumption side, there are more final goods to be consumed. On the expenditure side, as productivity of each input factor increases, the marginal products and hence, returns of capital and labor increase (consequently, households' direct income from this sector). Here, capital demand is growing over the initial periods as optimization of investments is always lagging behind due to the capital constraint, while the peak of supply and demand of labor occurs immediately as the input factor labor is partly substituted for the capital-energy bundle. In contrast to physical capital and labor, energy supply increases along with decreasing prices, at least for the initial 20 periods. The reason is the complementary link of energy with capital, whose 
adjustments are constrained. However, as they are not perfect complements, capital is party substituted with energy as the latter's adjustment is not restricted. However, in contrast to labor, more energy puts negative pressure on its marginal product and hence, energy prices decrease. As a direct consequence of drops in energy prices for households who also profit by increasing income, consumption of the durable goods increases. Again, the reason is its complimentary relationship with energy which makes the durable good - energy bundle cheaper.

In the energy sector, higher demand and supply of intermediate energy is mainly met by the fossil sector for two reasons. Unlike the renewable energy sector, who can only change its production by increasing investments which are temporary, the fossil energy sector is able to respond almost immediately to these changes by increasing the depletion of reserves. Moreover, although demand for both input factors increases, renewable energy is furthermore substituted by fossil intermediate energy during the initial periods as the elasticity of substitution of the latter is clearly higher. Demand for physical capital in both intermediate energy sectors increases to raise production along with higher capital returns. TFP in the final good sector converges to its long-run steady state due to its AR(1) process. Therefore, the swings of the remaining variables also diminish. As TFP in the final good sector converges to its long-run steady state, the amplitudes of the remaining variables also diminish.
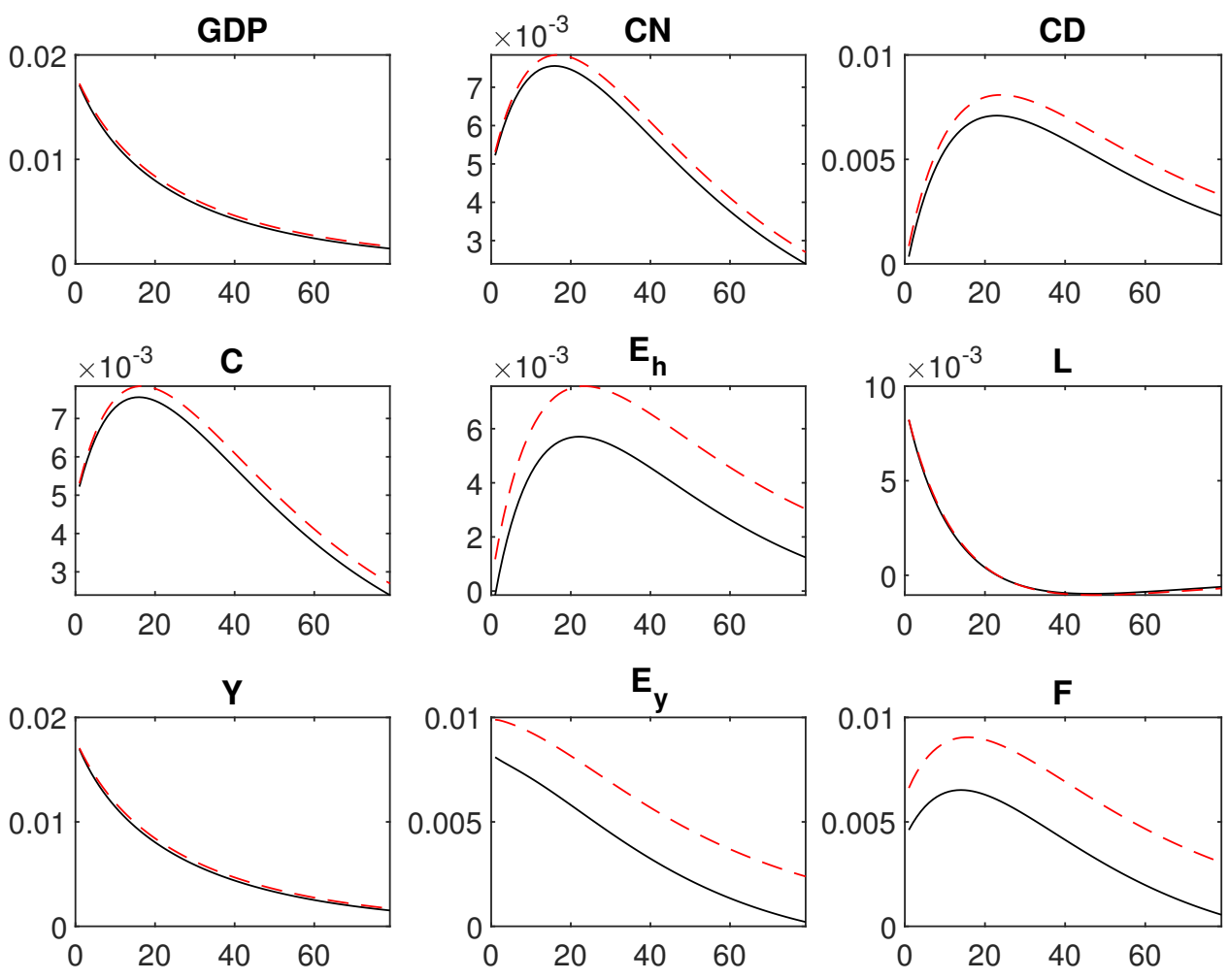

Figure 1: Bayesian IRF: Orthogonalized shock to $u_{-} A_{y}$. 

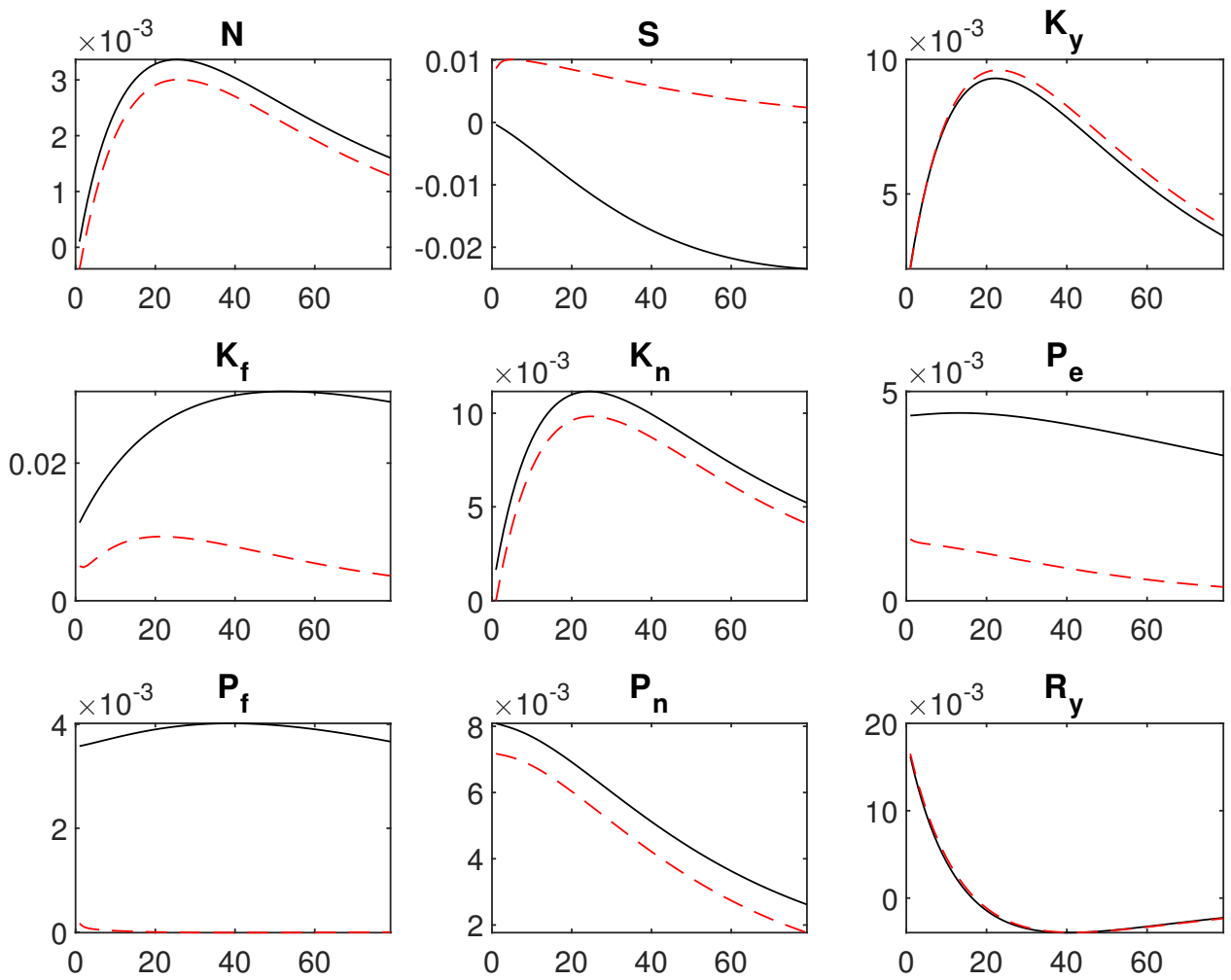

Figure 2: Bayesian IRF: Orthogonalized shock to $u_{-} A_{y}$.
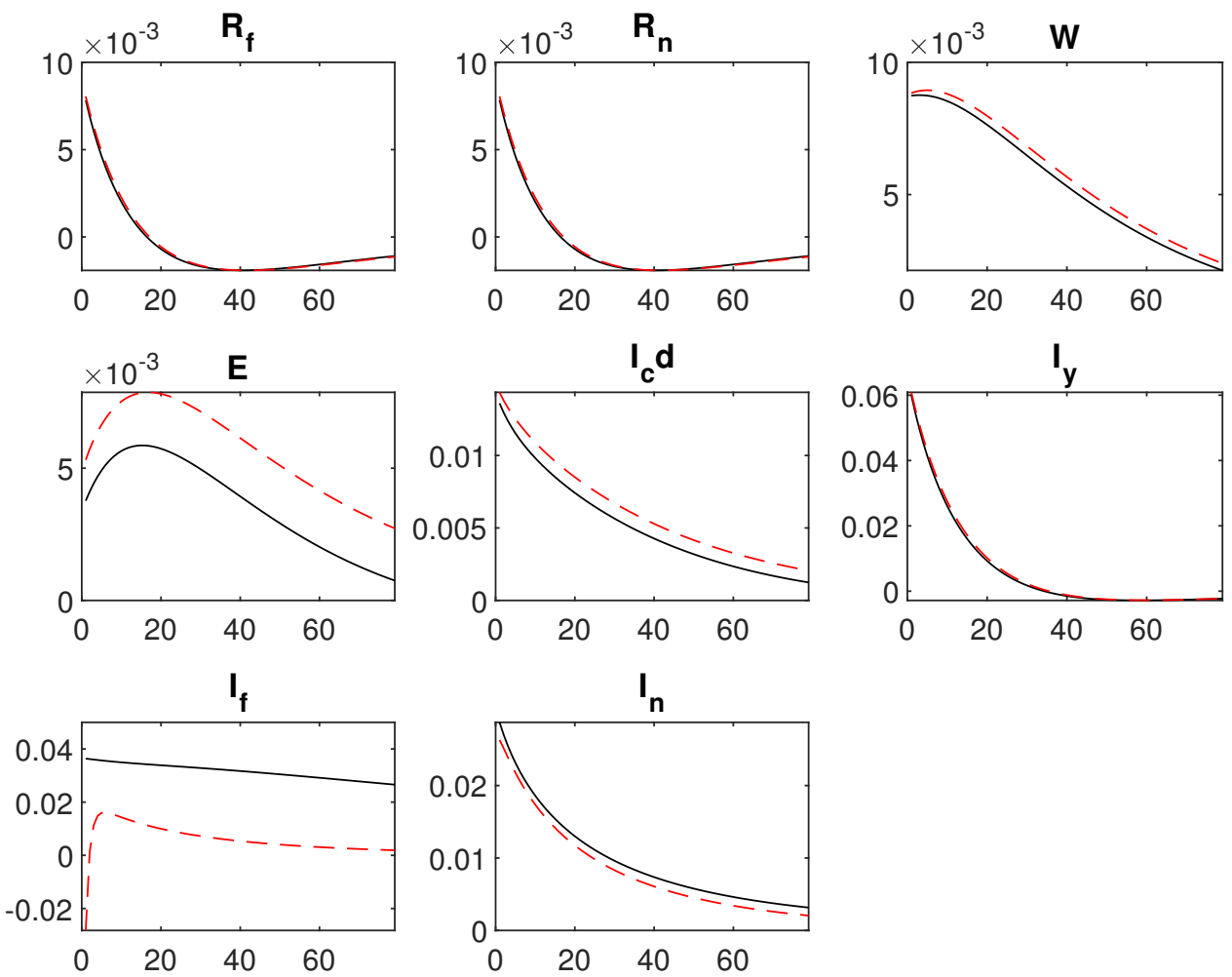

Figure 3: Bayesian IRF: Orthogonalized shock to $u_{-} A_{y}$.

The red dotted curves in figures $1-3$ describe the dynamics of the variables after a respective shock in TFP or finite resource stock. Comparing the baseline model and 
the model with replenishment, the results show a shift in the energy sector towards nonrenewable intermediate resources. While GDP, final good output as well as labor do not significantly deviate, the responds of the remaining variables is partly intensified. Because of the possibility to enhance the stock of finite resources through $R \& D$, the energy sector can immediately satisfy the increase in demand for the input factor energy by the final good sector. As a direct consequence, renewable intermediate energy is substituted by finite intermediate energy as the latter is more efficient (less costs and no time lag in all input factors). Hence, capital investments in finite energy increases while investments in physical capital of renewable energy diminishes with relatively constant interest rates. An explicit difference can be noticed for final energy prices which drop significantly compared to the baseline model. As a result, energy demand in the final good sector and household sector rise which also leads to a disproportional increase in consumption of durable goods. In sum, allowing for replenishment of the finite resource stock, the positive and negative responses persist longer compared to the basic model.

\subsection{Shock to TFP in the energy sector}

The dynamics of a positive shock in the energy sector are shown in figures $4-6$. As productivity and output in this sector increase, energy prices drop due to an oversupply of total energy. Consequently, the final good sector and households increase their demand which leads to higher investments in durable goods and the remaining input factors in the production functions. Altogether, this has a positive effect on output and GDP. Having higher productivity, the energy sector reduces its demand for intermediate energy which has negative effects on the price. The renewable energy sector suffers significantly more than the fossil energy sector and looses shares to the latter. The ability to quickly adjust production by changing the degree of depletion of reserves gives the fossil energy sector a flexible instruments and comparative advantage over the renewable energy sector. However, these effects diminish over the periods as the economy converges to its new longrun steady state. In contrast to a TFP shock, the quantity of energy peaks immediately as the shocked variable is presence in the energy production sector whose production function is not constrained by any time lag (in contrast to the remaining production functions). 

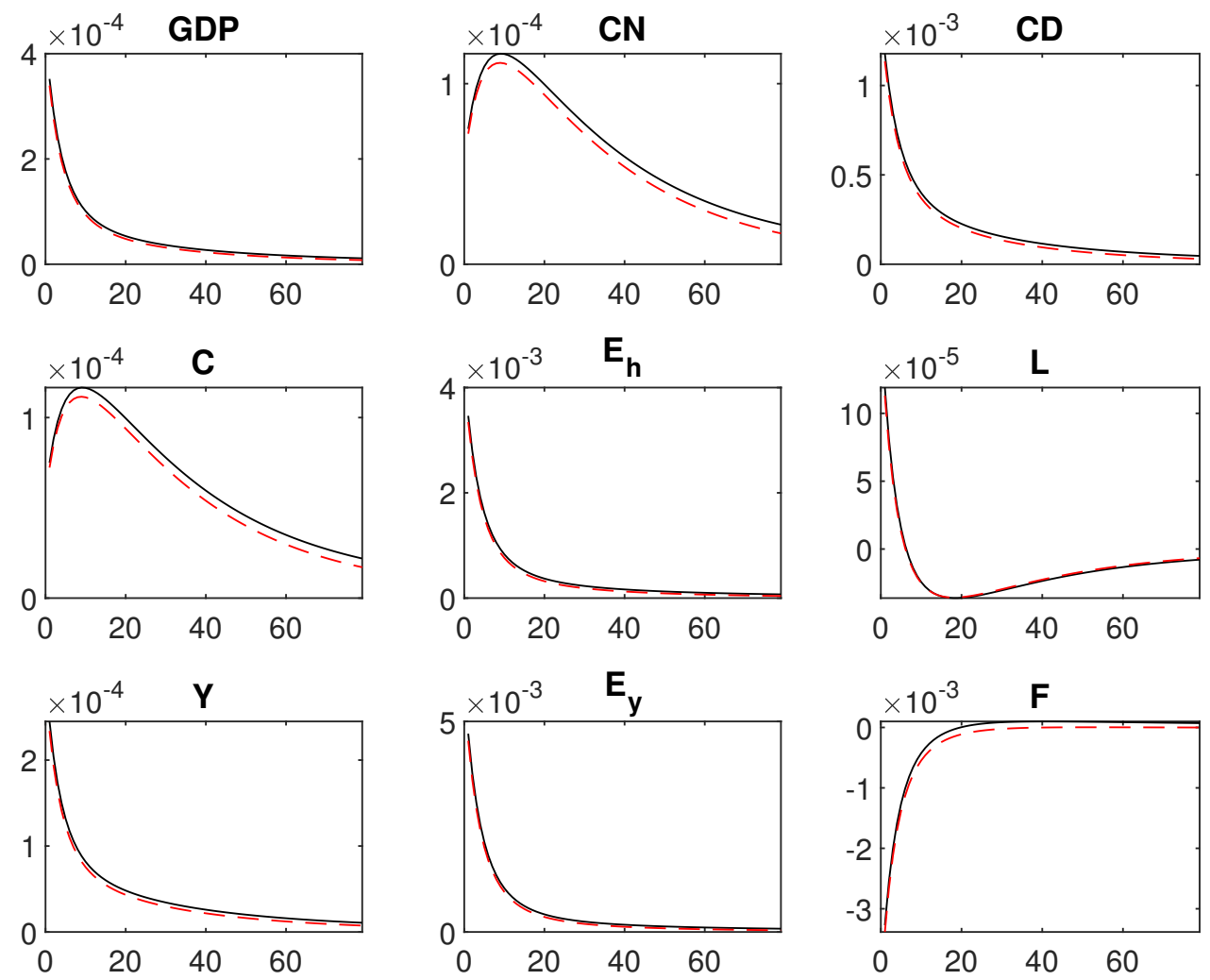

Figure 4: Bayesian IRF: Orthogonalized shock to $u_{-} A_{e}$.
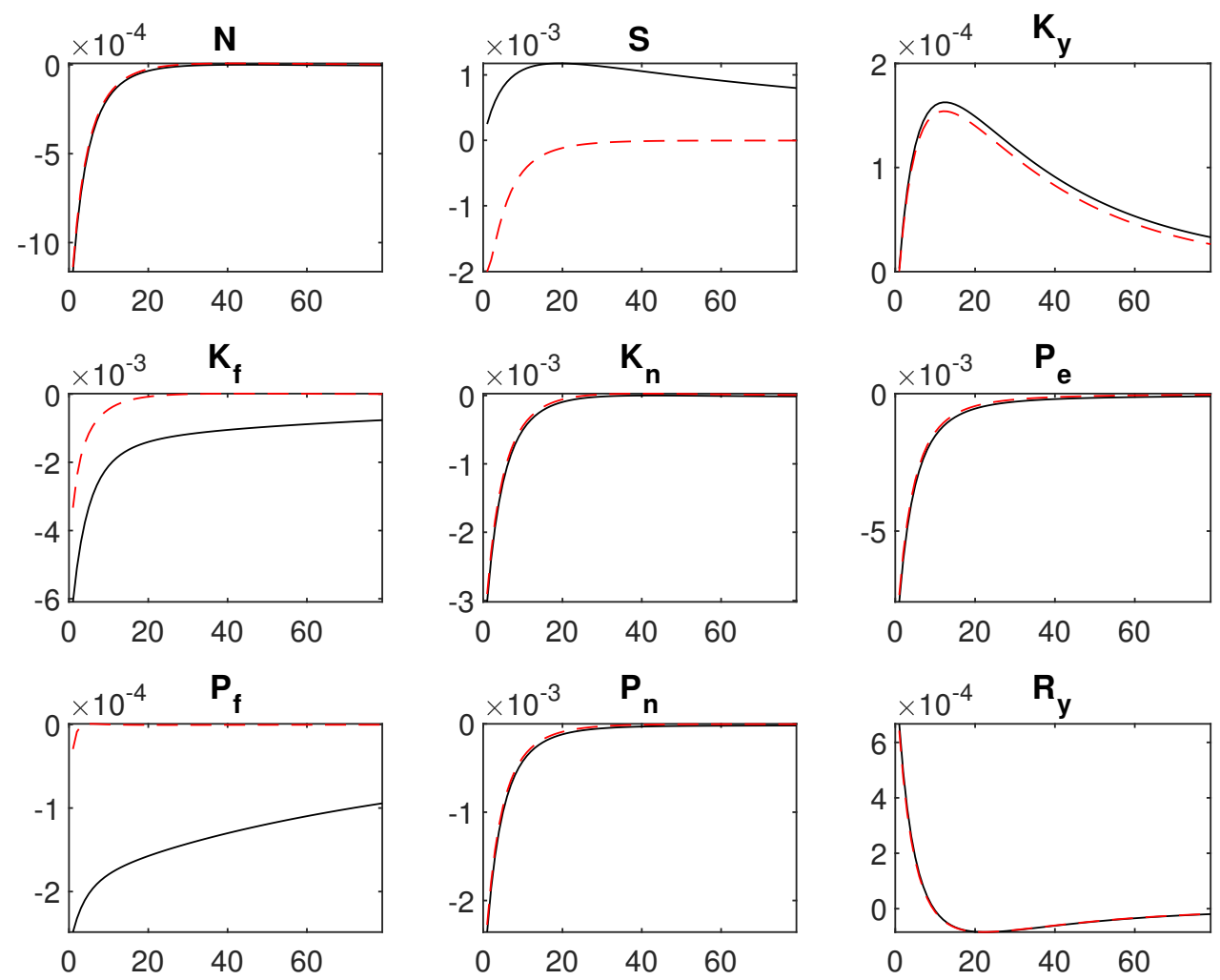

Figure 5: Bayesian IRF: Orthogonalized shock to $u_{-} A_{e}$. 

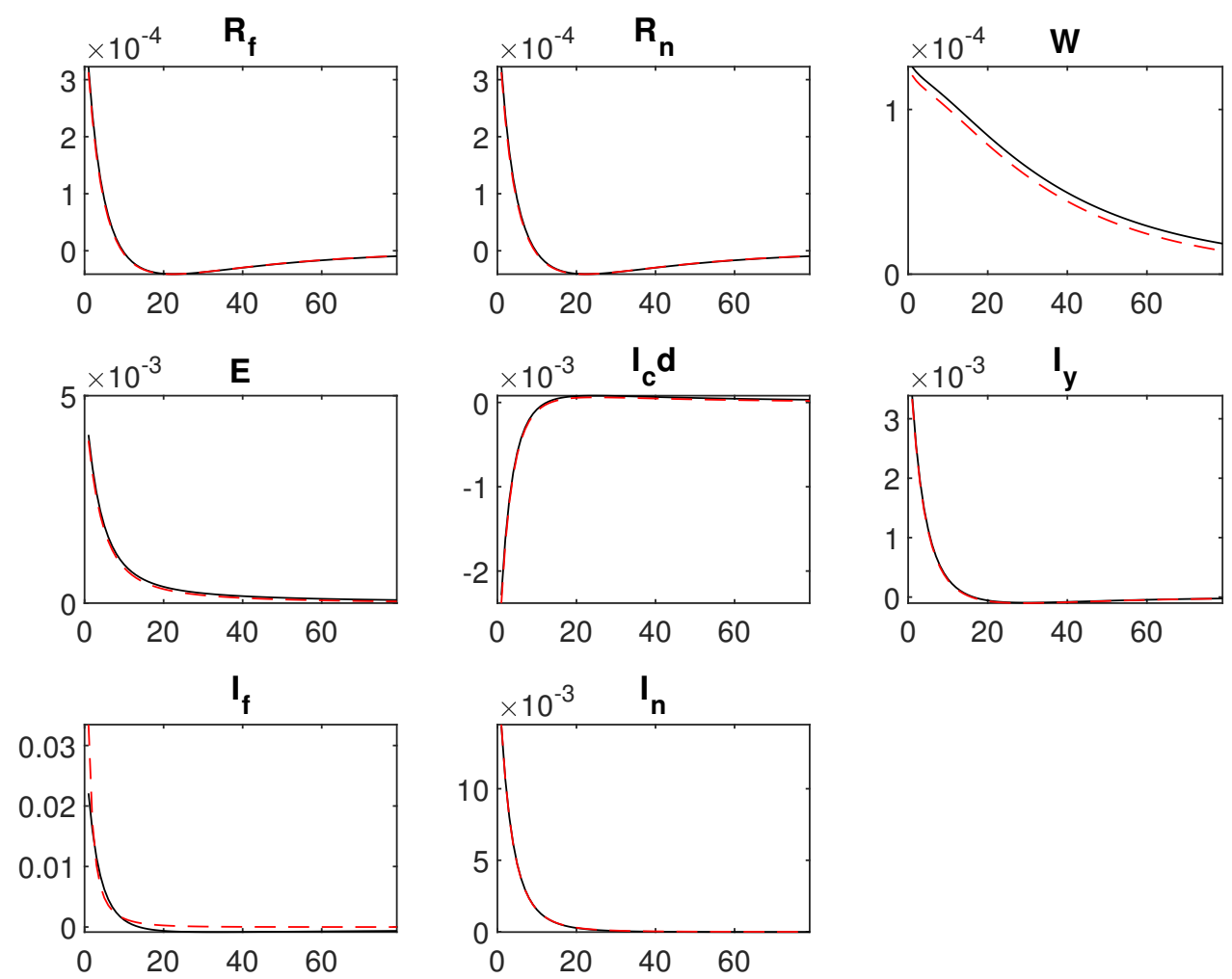

Figure 6: Bayesian IRF: Orthogonalized shock to $u_{-} A_{e}$.

Replenishment of the fossil resource stock enhances the impacts of a TFP shock in the energy sector. In particular variables related to the finite intermediate energy sector are affected which is shown by an increase in its physical capital stock, an increase in R\&D and hence in more intermediate energy output. Renewable energy responses are hardly affected, neither positively nor negatively which shows that replenishment is directly passed through the energy production and its purchasers.

\subsection{Shock to TFP in the fossil energy sector}

The effects of a positive TFP shock in the fossil energy sector are summarized in figures 7 - 9. Initially, such an impact pushes its intermediate energy output and slightly decreases energy prices. The depletion rate of reserves drops immediately as a direct consequence. Since the stock reserves is limited, a higher productivity allows the sector to save a valuable input factor. In the following, intermediate energy output declines which also negatively affects marginal productivity of physical capital. The energy sector substitutes fossil energy with renewable energy which leads to an increase in demand for physical capital in those sector. However, the substitution is not sufficient to compensate for the loss in intermediate fossil input due to the unequal elasticity of substitution. Hence, total energy output declines along with increasing prices while prices for intermediate energy inputs increases as well. The output in the final good sector as well as both consumption goods of the households decline which is mirrored by negative development 
of GDP. Overall, the medium-run impacts of a TFP shock are negative despite of the first positive developments.
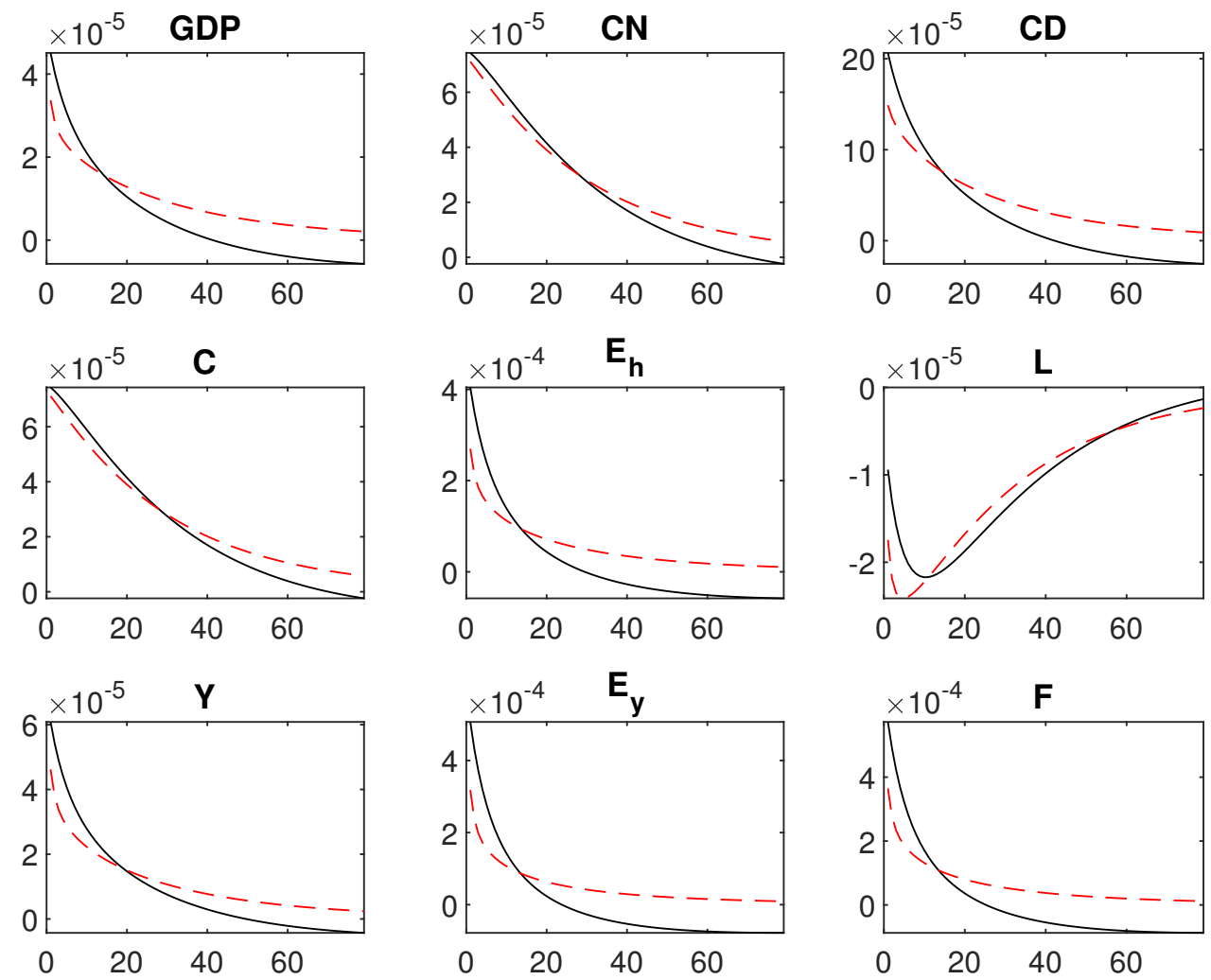

Figure 7: Bayesian IRF: Orthogonalized shock to $u_{-} A_{f}$.
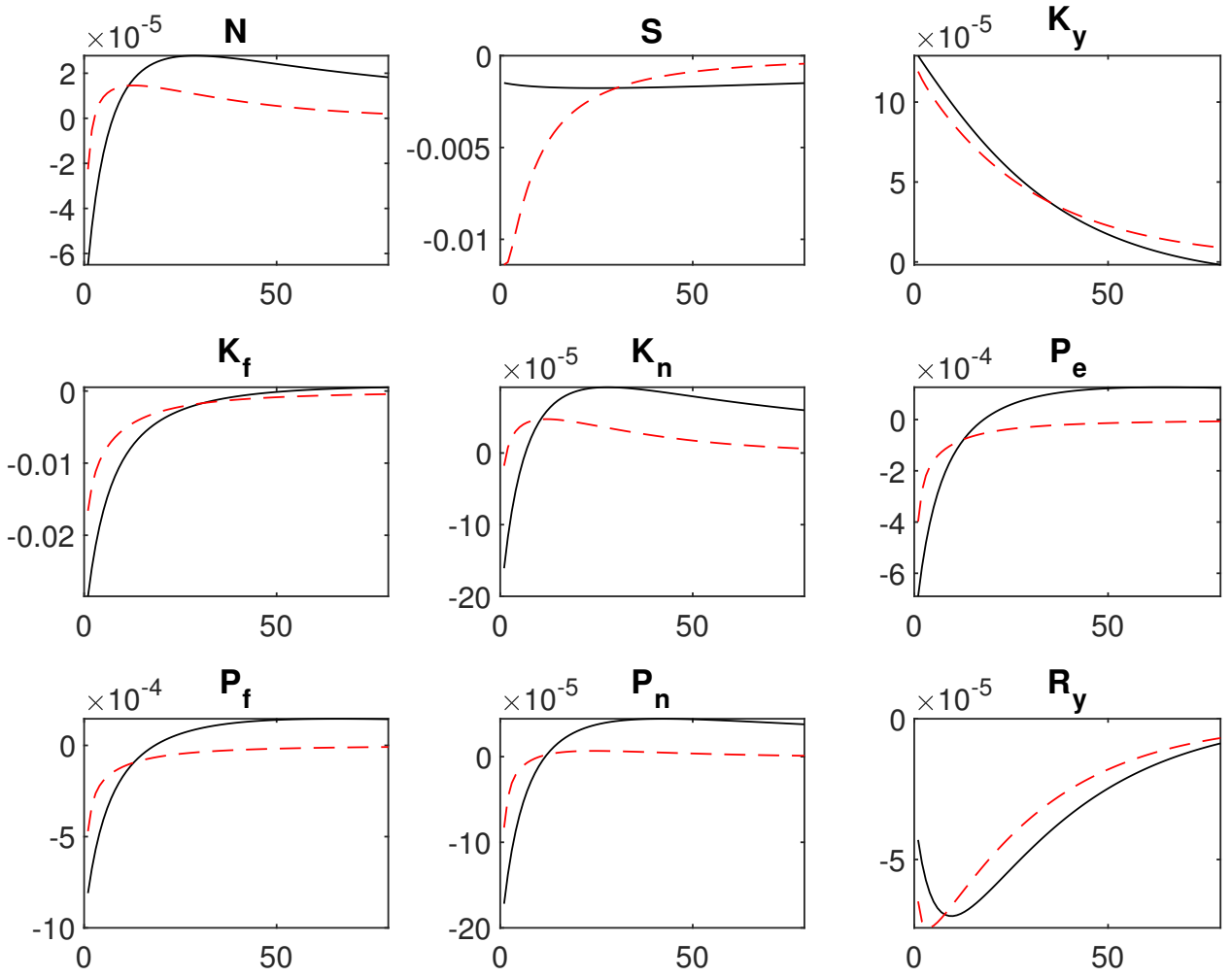

Figure 8: Bayesian IRF: Orthogonalized shock to $u_{-} A_{f}$. 

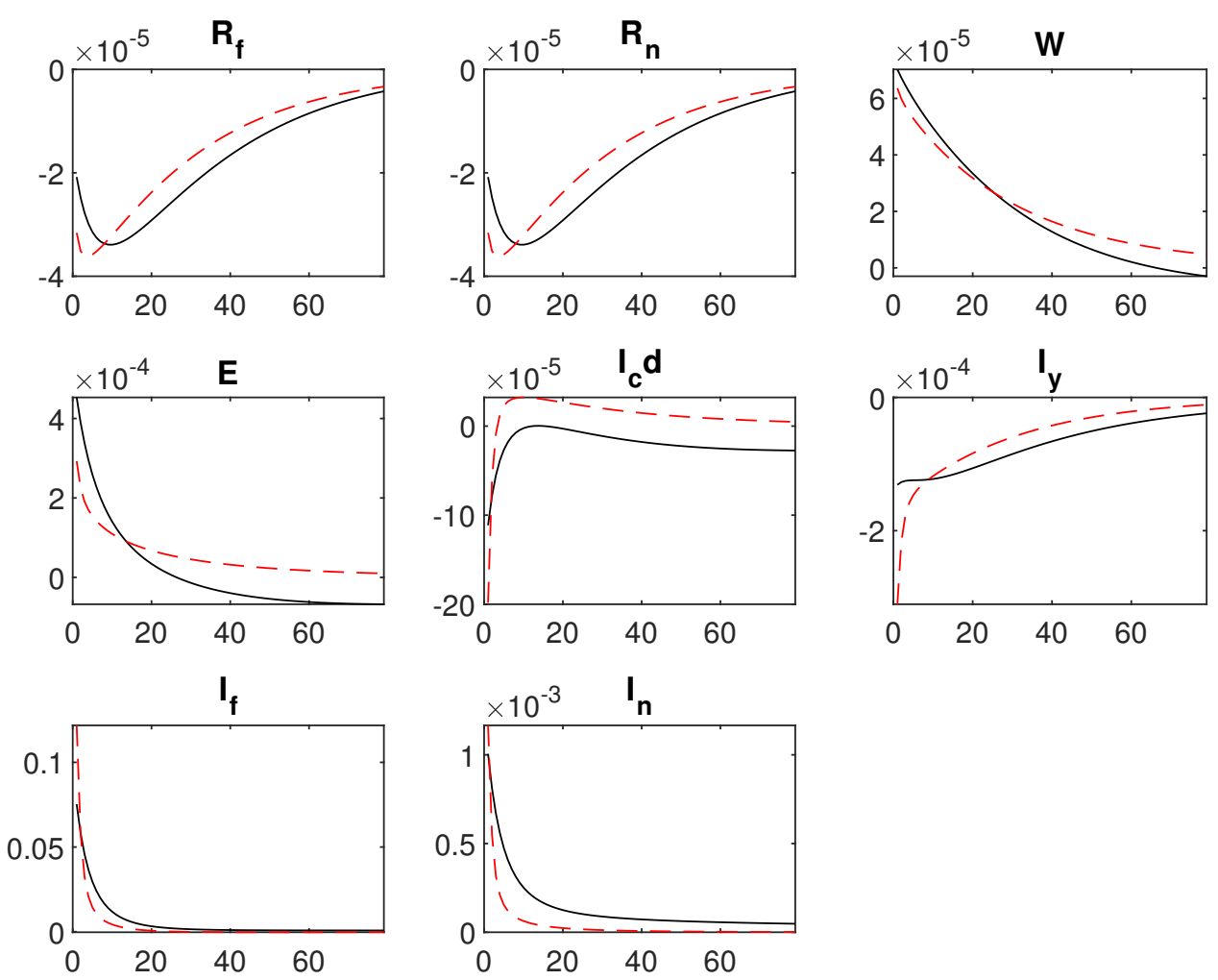

Figure 9: Bayesian IRF: Orthogonalized shock to $u_{-} A_{f}$.

Comparing the basic model and the model with replenishment, the dynamic responses do not deviate significantly. As the production function is constrained by a time lag in physical capital investments, its output is hardly affected by a larger resource stock due to R\&D. Consequently, a higher substitution of capital by replenishment is necessary to influence production which does not improve efficiency significantly as capital accumulation is also adjusted over time.

\subsection{Shock to TFP in the renewable energy sector}

In contrast to the fossil energy sector, a positive TFP shock in the renewable energy sector positively affects GDP in the medium run (see figures 10 - 12). The direct effects are an increase in output and decreasing prices in this sector. As less physical capital units have to be demanded to produce the same output, capital returns also decrease. The demand for fossil intermediate energy does not change significantly because of its high elasticity of substitution that brakes the possibility of substitution for cheaper renewable intermediate energy. Still, energy prices drop which stimulate investments in durable goods by households. For the final good sector, the lower energy costs also lead to an increase in demand for energy. However, due to its complementary relationship with capital, whose investment process is constrained, the energy-capital bundle is party substituted by labor. Overall, the effect on output is positive, also leading to an increase in consumption of non-durable goods by households. 

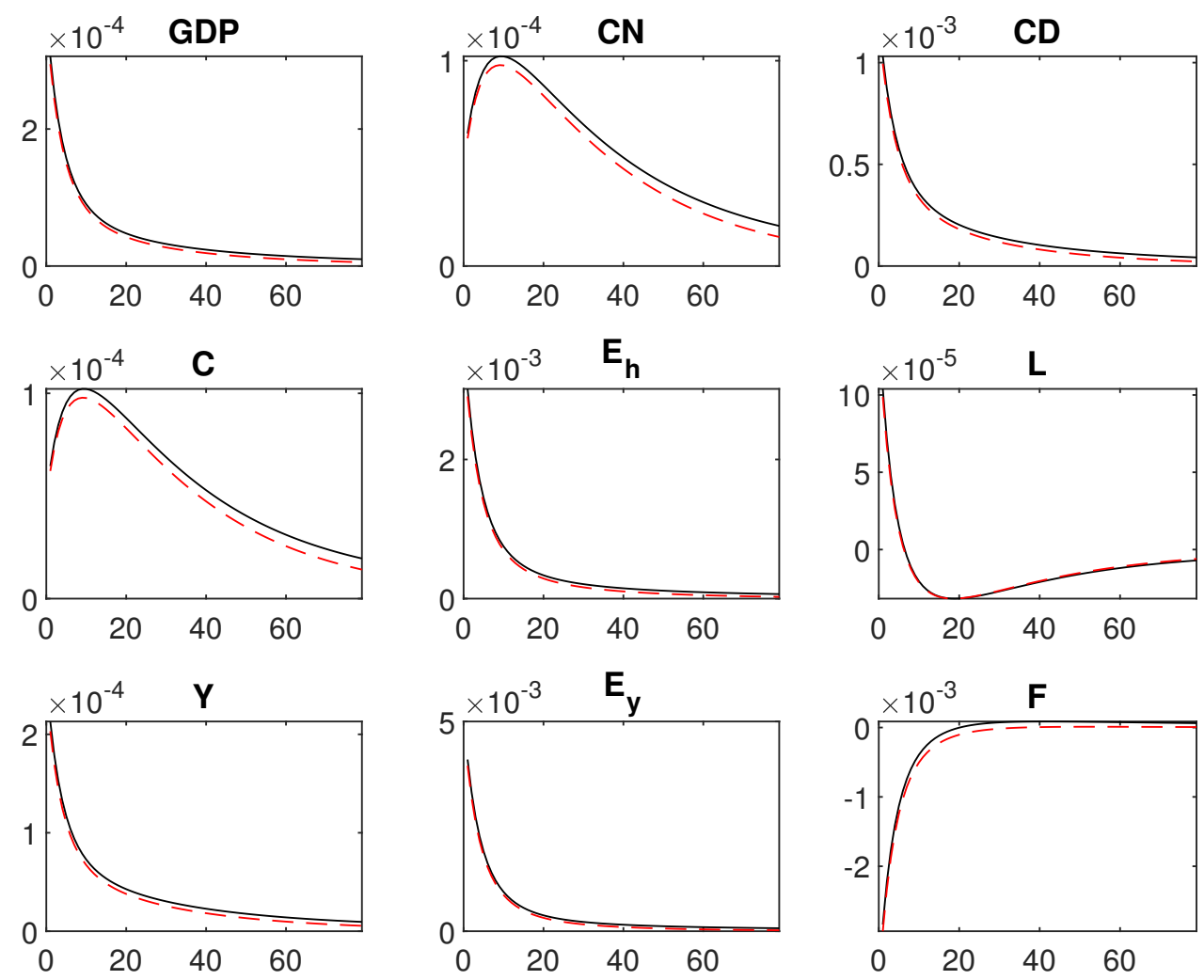

Figure 10: Bayesian IRF: Orthogonalized shock to $u_{-} A_{n}$.
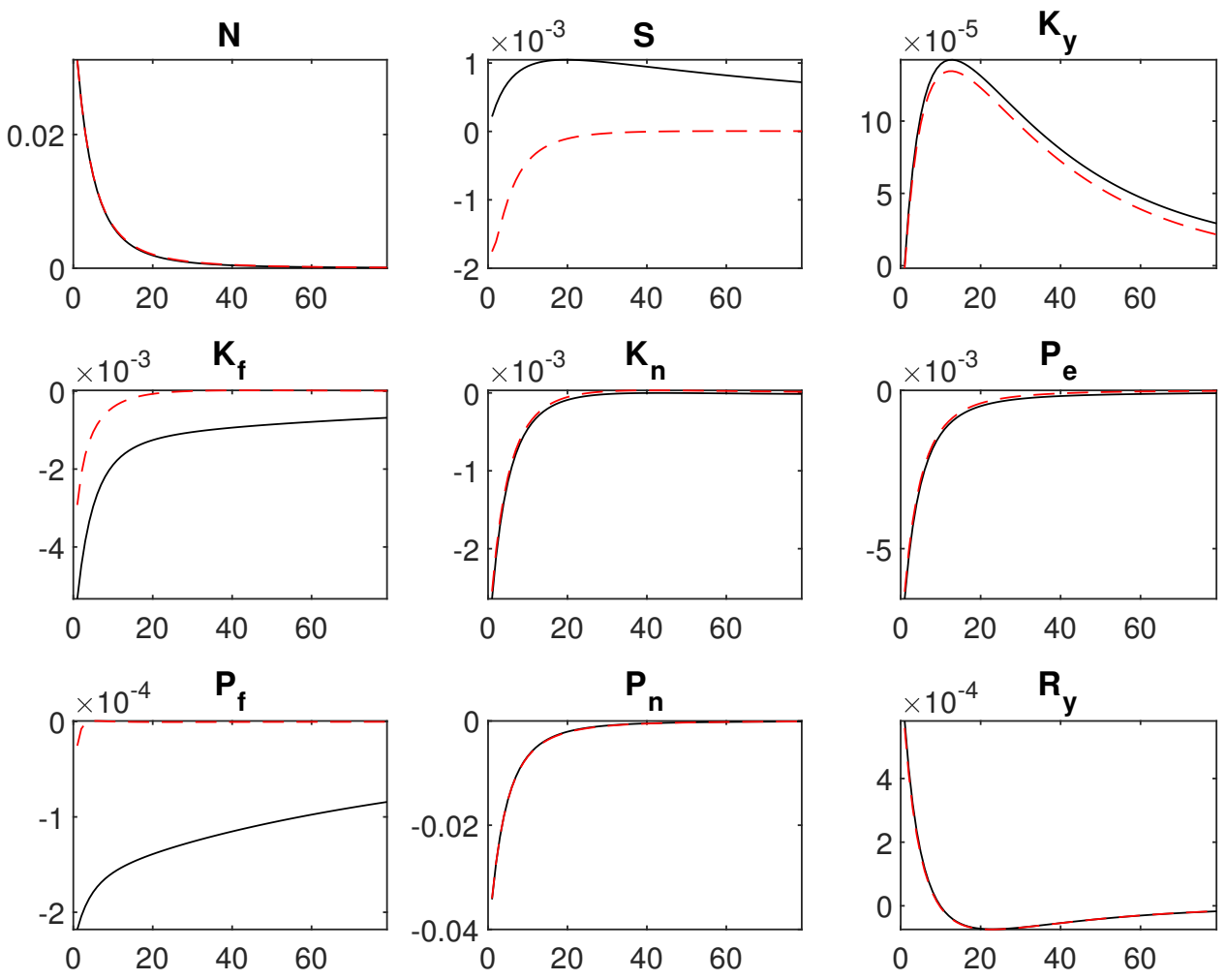

Figure 11: Bayesian IRF: Orthogonalized shock to $u_{-} A_{n}$. 

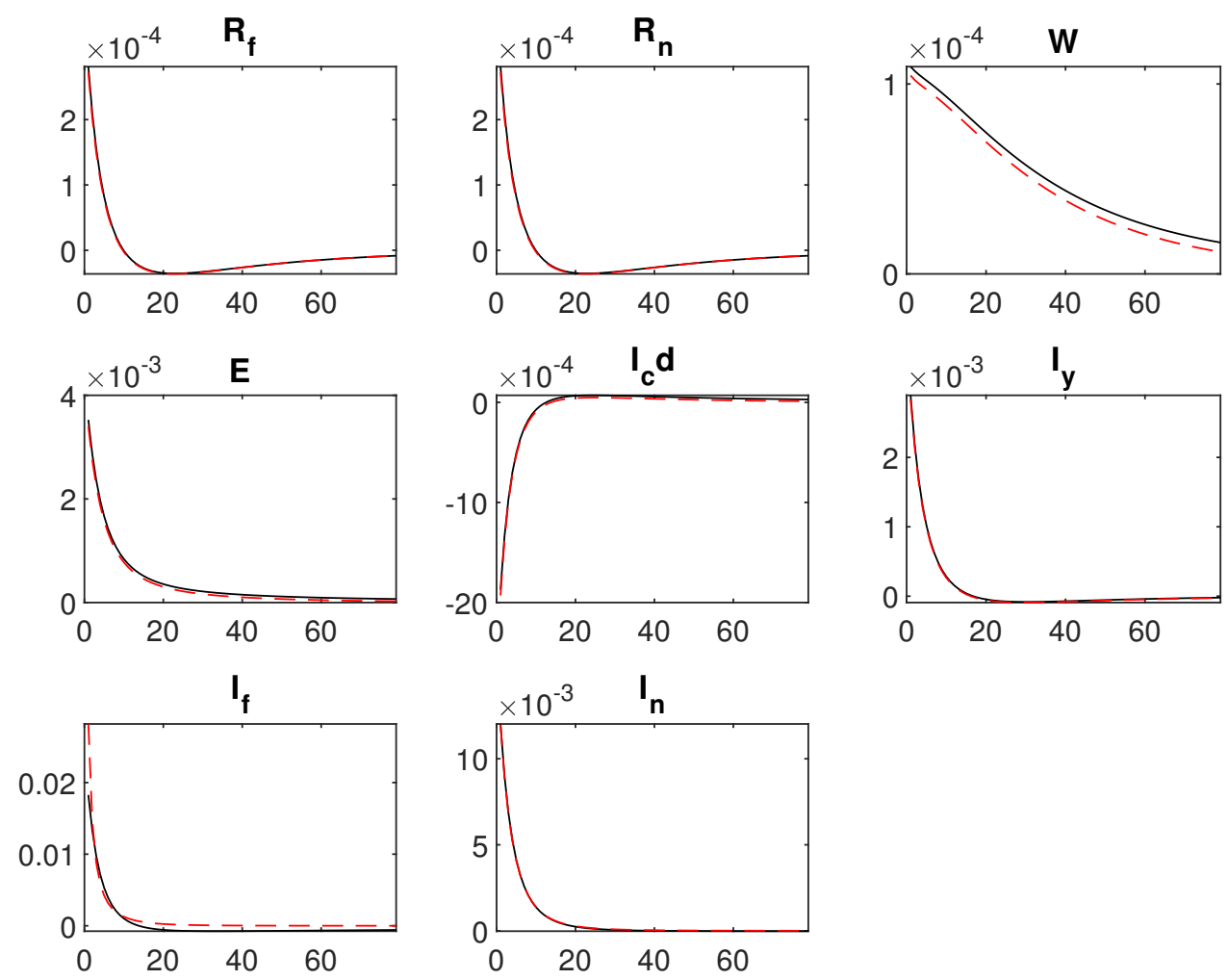

Figure 12: Bayesian IRF: Orthogonalized shock to $u_{-} A_{n}$.

Increasing the stock of finite resources through $R \& D$ does not affect the output of the renewable energy sector at all. However, due to the higher output of finite intermediate energy and the high elasticity of substitution, the final energy sector further increases its demand for finite energy. In sum, the final energy price faces negative pressure which positively influences energy demand, consumption, final output and consequently GDP.

\subsection{Shock to finite reserve stocks}

Figures 13 - 15 show the IRFs of a shock in the reserve constraint. A positive impact leads to a on-time unexpected reduction of reserve stock. The direct consequence is a sharp drop in fossil intermediate energy. Its price increases as this input factor is not easily substitutable with renewable intermediate energy by the energy sector. Hence, the finite resource sector reduces its costs resulting in lower demand for physical capital which is excessively available at first. On the contrary, the renewable energy sector sector indeed faces high demand, leading to an increase in physical capital. But its output does not offset the loss in fossil energy. As a results, the price of overall energy increases and exerts negative pressure on households and the production of final goods. In the short and medium term, GDP is negatively affected by a reduction of the reserve stock. 

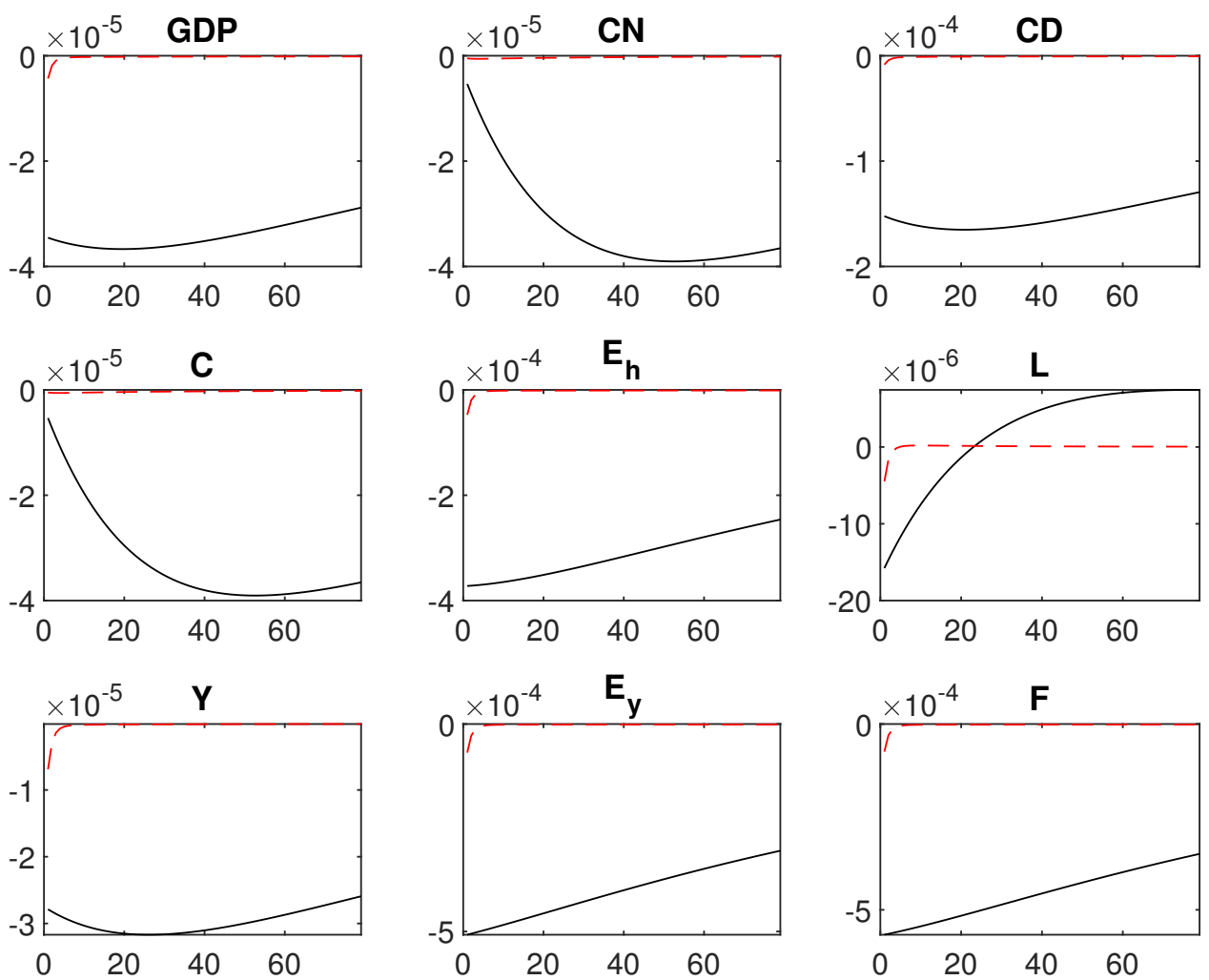

Figure 13: Bayesian IRF: Orthogonalized shock to $u_{-} S$.
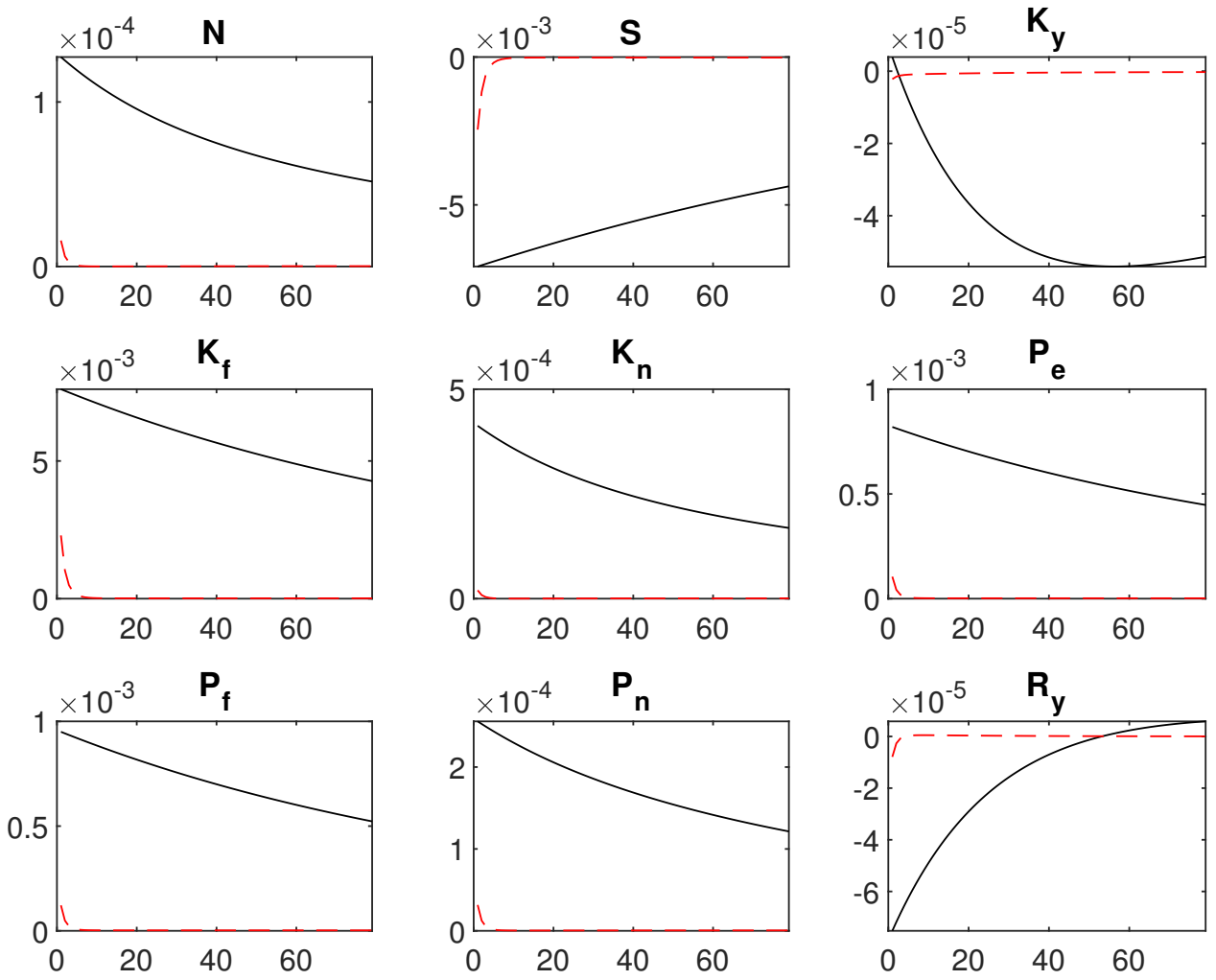

Figure 14: Bayesian IRF: Orthogonalized shock to $u_{-} S$. 

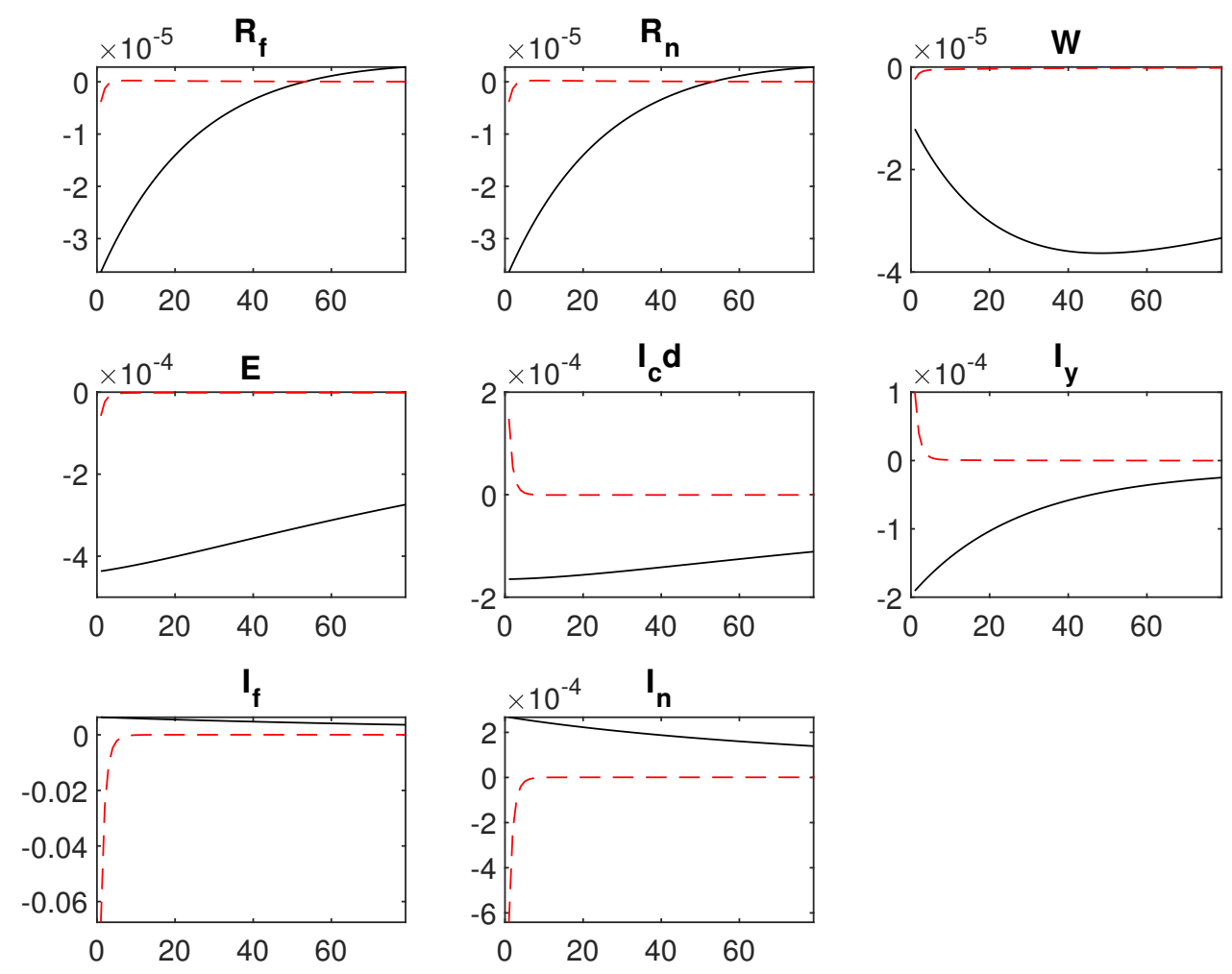

Figure 15: Bayesian IRF: Orthogonalized shock to $u_{-} S$.

In the model with replenishment of the finite resource stock, $R \& D$ intensifies the negative responses following a shock in the reserve. Rebuilding the reserve stock would go along with higher costs which are add to the price of energy. Hence, the finite energy sector reduces its costs by decreasing its effort in R\&D. In sum, the economy suffers more from a reserve shock as the renewable energy sector is cannot compensate the loss from the finite energy sector due to its small size.

The dynamic responses confirm the findings by Dhawan and Jeske (2008) concerning the behavior of the disruption of fixed capital. This also explains the low weight of TFP shock in the energy sectors which are further pointed out below. As the households have further channels available, they are more flexible in their investment decision. Facing a shock in TFP $\left\{A_{e}, A_{f}, A_{n}\right\}$ leads to adjustments of capital investments in the final good production which, however, are dominated by adjustments of investments in durable goods by the households. To be more precise, the negative response of capital investments in the final good sector after a reduction in the non-renewable reserve stock are less than the reduction of durable goods purchases (compare $I_{C D}$ and $I_{y}$ in figure 15). Overall, the present paper includes four channels to rebalance investments while Dhawan and Jeske consider only two. 


\section{Shock decomposition}

Table 7 comprise the importance of the effects by the six shocks on the the main endogenous variables in the model relative to each other. In other words, it shows the contribution of each shock to the variance in the variables. In contrast to other papers, we distinguish between several productivity shocks which are allocated to the respective sectors' production functions. Unsurprisingly, total factor productivity has the most influential pressure on output in its respective sector except for final energy. On the one side, the bounded intermediate fossil energy and its high share seems to impair final energy production significantly. On the other side, the variance in technological progress of final energy is small and consequently does not notably boost output. Apparently, productivity in final good production has the most important influence on overall GDP. Even on consumption of non-durable goods, it shows a high importance, next to the shock in consumer taste. The role of the latter is obvious as it carries out direct influence on consumption. The remaining shock processes are negligible with respect to output.

Considering durable goods, more than one-third in the variance is explained by a one-time changes in the finite reserve stock. It also explains more that two-third of the variance of energy related variables such as demand and supply of intermediate energy, fossil intermediate resources, and capital used in the finite sector. Due to a change in the finite stock of reserves and hence, the efficiency of the non-renewable sector, even the renewable sector is strongly affected by facing countermeasures in its usage of physical capital.

The variances in final production technological progress and stock of reserves gain further importance by inspecting the model allowing for reserve resource exploration. This happens at the expense of the remaining shocks as their explanationary shares decrease. But the differences are moderate. Fluctuations though the remaining shocks are absorbed by the possibility to adjust the exploration rate $D$ which allows the finite resource sector some degree of flexibility.

Table 7: Posterior mean variance decomposition (in percent)

\begin{tabular}{lccccccc}
\hline & $u_{-} A_{-} e$ & $u_{-} A_{-} n$ & $u_{-} A_{-} y$ & $u_{-} A_{-} f$ & $u_{-} T$ & $u_{-} S$ & $u_{-} T D$ \\
\hline$G D P$ & 0.04 & 0.02 & 93.84 & 0.01 & 5.94 & 0.01 & 0.14 \\
$C N$ & 0.01 & 0.00 & 29.10 & 0.00 & 70.85 & 0.00 & 0.03 \\
$C D$ & 0.39 & 0.15 & 47.66 & 0.01 & 31.24 & 0.15 & 20.39 \\
$C$ & 0.03 & 0.01 & 69.78 & 0.00 & 30.06 & 0.01 & 0.10 \\
$E \_h$ & 5.41 & 2.03 & 51.24 & 3.20 & 36.88 & 1.11 & 0.13 \\
\hline \multicolumn{5}{c}{} \\
\hline
\end{tabular}


Table 7: (continued)

\begin{tabular}{|c|c|c|c|c|c|c|c|}
\hline & $u_{-} A_{-} e$ & $u \_A \_n$ & $u_{-} A_{-} y$ & $u_{-} A_{-} f$ & $u_{-} T$ & $u_{-} S$ & $u_{-} T D$ \\
\hline$L$ & 0.05 & 0.02 & 50.95 & 0.06 & 48.73 & 0.00 & 0.19 \\
\hline$Y$ & 0.04 & 0.01 & 93.87 & 0.03 & 5.89 & 0.01 & 0.14 \\
\hline$E_{-} y$ & 12.63 & 4.63 & 62.43 & 10.82 & 7.49 & 1.66 & 0.33 \\
\hline$F$ & 2.09 & 0.79 & 65.75 & 10.15 & 18.52 & 2.44 & 0.25 \\
\hline$N$ & 0.17 & 77.86 & 15.99 & 0.00 & 5.88 & 0.04 & 0.05 \\
\hline$S$ & 0.36 & 0.17 & 73.27 & 0.41 & 16.66 & 9.03 & 0.10 \\
\hline$K_{-} y$ & 0.04 & 0.01 & 74.61 & 0.00 & 24.78 & 0.02 & 0.54 \\
\hline$K_{-} f$ & 0.50 & 0.22 & 73.04 & 3.37 & 16.83 & 5.92 & 0.12 \\
\hline$K_{-} n$ & 0.94 & 0.37 & 68.91 & 0.01 & 29.31 & 0.20 & 0.26 \\
\hline$P_{-} e$ & 19.27 & 7.02 & 47.59 & 16.91 & 7.15 & 2.01 & 0.04 \\
\hline$P_{-} f$ & 4.39 & 1.53 & 56.05 & 25.42 & 9.30 & 3.27 & 0.05 \\
\hline$P \_n$ & 2.38 & 55.03 & 35.56 & 2.74 & 4.15 & 0.10 & 0.04 \\
\hline$R_{-} y$ & 0.19 & 0.07 & 63.34 & 0.18 & 35.96 & 0.00 & 0.27 \\
\hline$R_{-} f$ & 12.39 & 4.24 & 7.89 & 74.87 & 0.49 & 0.12 & 0.00 \\
\hline$R \_n$ & 11.28 & 3.87 & 46.12 & 15.58 & 22.98 & 0.00 & 0.16 \\
\hline$W$ & 0.03 & 0.01 & 83.05 & 0.01 & 16.77 & 0.01 & 0.11 \\
\hline$A_{-} y$ & 0.00 & 0.00 & 100.00 & 0.00 & 0.00 & 0.00 & 0.00 \\
\hline$A_{-} e$ & 100.00 & 0.00 & 0.00 & 0.00 & 0.00 & 0.00 & 0.00 \\
\hline$A_{-} f$ & 0.00 & 0.00 & 0.00 & 100.00 & 0.00 & 0.00 & 0.00 \\
\hline$A \_n$ & 0.00 & 100.00 & 0.00 & 0.00 & 0.00 & 0.00 & 0.00 \\
\hline$A_{-} u$ & 0.00 & 0.00 & 0.00 & 0.00 & 0.00 & 100.00 & 0.00 \\
\hline$E$ & 9.83 & 3.65 & 59.54 & 7.38 & 17.75 & 1.62 & 0.23 \\
\hline$I_{-} c d$ & 0.40 & 0.14 & 2.25 & 0.01 & 11.45 & 0.01 & 85.74 \\
\hline$I_{-} y$ & 0.07 & 0.02 & 31.40 & 0.05 & 28.15 & 0.00 & 40.32 \\
\hline$I_{-} f$ & 5.55 & 1.97 & 27.73 & 50.08 & 6.03 & 7.89 & 0.76 \\
\hline$I \_n$ & 20.35 & 7.25 & 22.49 & 0.05 & 44.50 & 0.35 & 5.02 \\
\hline
\end{tabular}




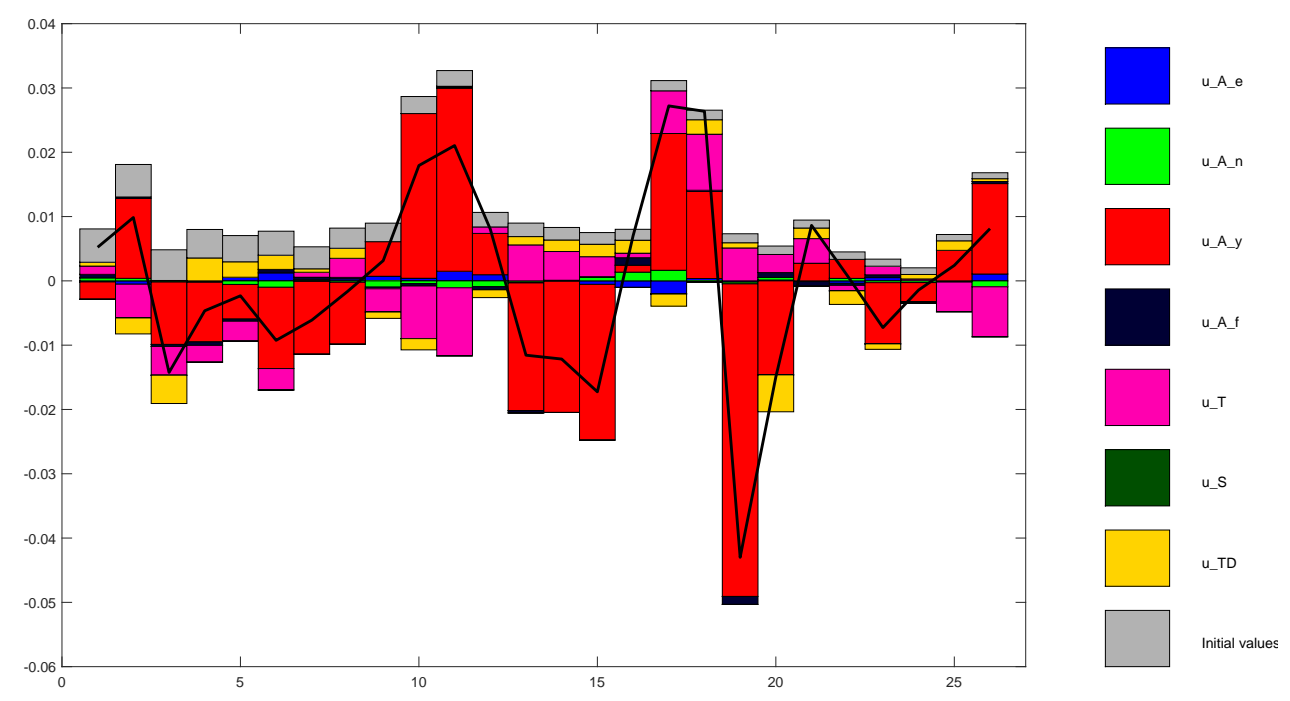

Figure 16: Historical shock decomposition: GDP.

To investigate further how shocks affect deviation from steady state of the German economy over the sample period figure 16 presents the shock decomposition of historical business cycles of Germany between 1991-2014. Overall, total factor productivity in the final good production $u_{A y}$ is still the most influential variance explaining the cycles of the economy as shown in literature. Clearly less important than TFP for final goods is the taste shifter shock $u_{T}$ followed by shocks in the stock of reserves. Finite energy productivity does not play an important role in GDP fluctuation despite of contribution the predominate share to final energy production which is an input factor in good production and consumption. On the one side, the main impulse from the finite resource sector originates within the resource stock which is the most limiting factor of this sector. On the other side, energy consumers smooth the effects though shifting to alternative, substitutable components. The respective decomposition taking the model with resource exploration into account is equivalent.

Altogether, the variance decomposition shows that the share of fluctuations resulting from changes in productivity within the energy sectors is negligible. The overall share explaining business cycles comes from TFP in the final good sector. However, it becomes also clear that within the energy sectors, stochastic changes of the reserve stock certainly do affect GDP, albeit slightly.

\section{Conclusion}

We have constructed a RBC model where energy is consumed by final good production and households. Furthermore, energy is composed from fossil intermediate energy and renewable energy which are each endogenously mined or generated in the model. To avoid exaggerated disruptive investment dynamics, households can invest in a durable good stock next to the usual investment channels to each production sector. We have 
estimated this RBC model using Bayesian techniques and based on data from the German economy. MCMC methods have confirmed a complementary relationship between durable goods and energy consumption in the household sector as well as between physical capital and energy consumption in the final good sector.

In our estimated RBC model, we find a complementary relationship between durable goods and energy consumption in the household sector as well as between physical capital and energy consumption in the final good sector. Furthermore, a TFP shock in the (final and intermediate) energy sectors has a larger effect on durable good purchases than on capital investments in the final good production going along with Dhawan and Jeske (2008). Nevertheless, even in the model at hand with endogenous price determination of energy, TFP in final good production is still the major contributor to business cycle formation. Moreover, despite of allowing the replenish the constrained fossil stock in an extension, the dynamic responds of the variables do not deviate from the basic model.

For future research, this RBC model can be extended to investigate policy strategies to regulate the usage of different source of intermediate energy. As such, instruments as taxes or subsidies can be applied to perform artificial market imperfections. Under this aspect, it is interesting to analyze inequality of welfare with heterogeneous households which may change on the basis of the corresponding policy instrument. 


\section{References}

Sakib Amin and Shaikh S Ferdaus. The macroeconomics of energy price shocks and electricity market reforms: The case of bangladesh. 2015.

Amedeo Argentiero, Carlo Andrea Bollino, Silvia Micheli, and Constantin Zopounidis. Renewable energy sources policies in a bayesian dsge model. Renewable Energy, 120: 60-68, 2018.

Ben Bernanke, Mark Gertler, and Mark W Watson. Oil shocks and aggregate macroeconomic behavior: The role of monetary policy: A reply. Journal of Money, Credit, and Banking, 36(2):287-291, 2004.

Ben S Bernanke, Mark Gertler, Mark Watson, Christopher A Sims, and Benjamin M Friedman. Systematic monetary policy and the effects of oil price shocks. Brookings papers on economic activity, 1997(1):91-157, 1997.

BGR. Energy study 2016. reservesm resources and availability of energy resources. 20: $180,2016$.

Stanley W Black. Learning from adversity: Policy responses to two oil shocks. International Finance Section, Department of Economics, Princeton University, 1985.

Henning Bohn and Robert T Deacon. Ownership risk, investment, and the use of natural resources. American Economic Review, 90(3):526-549, 2000.

Lorenzo Caliendo, Fernando Parro, Esteban Rossi-Hansberg, and Pierre-Daniel Sarte. The impact of regional and sectoral productivity changes on the us economy. The Review of economic studies, 85(4):2042-2096, 2017.

Rajeev Dhawan and Karsten Jeske. Energy price shocks and the macroeconomy: the role of consumer durables. Journal of Money, Credit and Banking, 40(7):1357-1377, 2008.

Eurostat. Consumption of energy, 2017. URL http://ec.europa.eu/eurostat/ statistics-explained/index.php?title=Consumption_of_energy.

Eurostat. Renewable energy statistics, 2018. URL http://ec.europa.eu/eurostat/ statistics-explained/index.php/Renewable_energy_statistics.

Jesus Fernandez-Villaverde and Dirk Krueger. Consumption and saving over the life cycle: How important are consumer durables? Macroeconomic dynamics, 15(5):725$770,2011$.

Mary G. Finn. Variance properties of solow's productivity residual and their cyclical implications. Journal of Economic Dynamics and Control, 19(5):1249 - 1281, 1995. 
ISSN 0165-1889. doi: https://doi.org/10.1016/0165-1889(94)00826-4. URL http:// www.sciencedirect.com/science/article/pii/0165188994008264.

Jeremy Greenwood, Richard Rogerson, and Randall Wright. Household production in real business cycle theory. frontiers of Business cycle research, 15774, 1995.

Tommaso Mancini Griffoli. Dynare user guide. an introduction to the solution and estimation of dsge models. Manuscript, http://www. cepremap. cnrs. fr/dynare, 2007.

Isaac Gross, James Hansen, et al. Reserves of natural resources in a small open economy. Reserve Bank of Australia, 2013.

James D Hamilton. Oil and the macroeconomy since world war ii. The Journal of Political Economy, pages 228-248, 1983.

Ana María Herrera. Oil price shocks, inventories, and macroeconomic dynamics. Macroeconomic Dynamics, 22(3):620-639, 2018.

Harold Hotelling. The economics of exhaustible resources. Journal of political Economy, 39(2):137-175, 1931.

Nikolay Hristov. The ifo dsge model for the german economy. Technical report, ifo Working Paper, 2016.

Pascal Jacquinot, Mika Kuismanen, Ricardo Mestre, and Martin Spitzer. An assessment of the inflationary impact of oil shocks in the euro area. The Energy Journal, pages 49-83, 2009.

Lutz Kilian. The economic effects of energy price shocks. Journal of Economic Literature, 46(4):871-909, 2008.

In-Moo Kim and Prakash Loungani. The role of energy in real business cycle models. Journal of Monetary Economics, 29(2):173-189, 1992.

Sylvain Leduc and Keith Sill. A quantitative analysis of oil-price shocks, systematic monetary policy, and economic downturns. Journal of Monetary Economics, 51(4): 781-808, 2004.

Prakash Loungani. Oil price shocks and the dispersion hypothesis. The Review of Economics and Statistics, pages 536-539, 1986.

Charles F Mason, Rémi Morin Chassé, et al. The transition to renewable energy. Technical report, CESifo Group Munich, 2018.

Bennett T McCallum. Real business cycle models, 1988. 
Knut Anton Mork. Oil and the macroeconomy when prices go up and down: an extension of hamilton's results. Journal of political Economy, 97(3):740-744, 1989.

Knut Anton Mork and Robert E Hall. Energy prices and the us economy in 1979-1981. The Energy Journal, 1(2):41-53, 1980.

OECD. OECD economic outlook no. 102 (edition 2017/2), oct 2012.

Masao Ogaki and Carmen M Reinhart. Measuring intertemporal substitution: The role of durable goods. Journal of political Economy, 106(5):1078-1098, 1998.

Charles I Plosser. Understanding real business cycles. Journal of Economic Perspectives, 3(3):51-77, 1989.

Marco Ratto and Nikolay Iskrev. Identification analysis of dsge models with dynare. MONFISPOL, 225149:26, 2011.

Julio J Rotemberg and Michael Woodford. Imperfect competition and the effects of energy price increases on economic activity. Journal of Money, Credit and Banking, 28 (4):549-577, 1996.

Marcelo Sánchez. Oil shocks and endogenous markups: results from an estimated euro area dsge model. International Economics and Economic Policy, 8(3):247-273, 2011.

Torsten Schmidt and Tobias Zimmermann. Effects of oil price shocks on german business cycles. 2005.

Robert M Solow. Intergenerational equity and exhaustible resources. The review of economic studies, 41:29-45, 1974.

David I Stern. The role of energy in economic growth. Annals of the New York Academy of Sciences, 1219(1):26-51, 2011.

Joseph Stiglitz. Growth with exhaustible natural resources: efficient and optimal growth paths. The review of economic studies, 41:123-137, 1974.

James Tobin, Edmund S Phelps, William Poole, Martin Feldstein, Hendrik Houthakker, Franco Modigliani, Patric Hendershott, Benjamin Friedman, George Perry, James Duesenberry, et al. Stabilization policy ten years after. Brookings Papers on Economic Activity, 1980(1):19-89, 1980. 


\section{Appendix}

\section{A Model Overview}

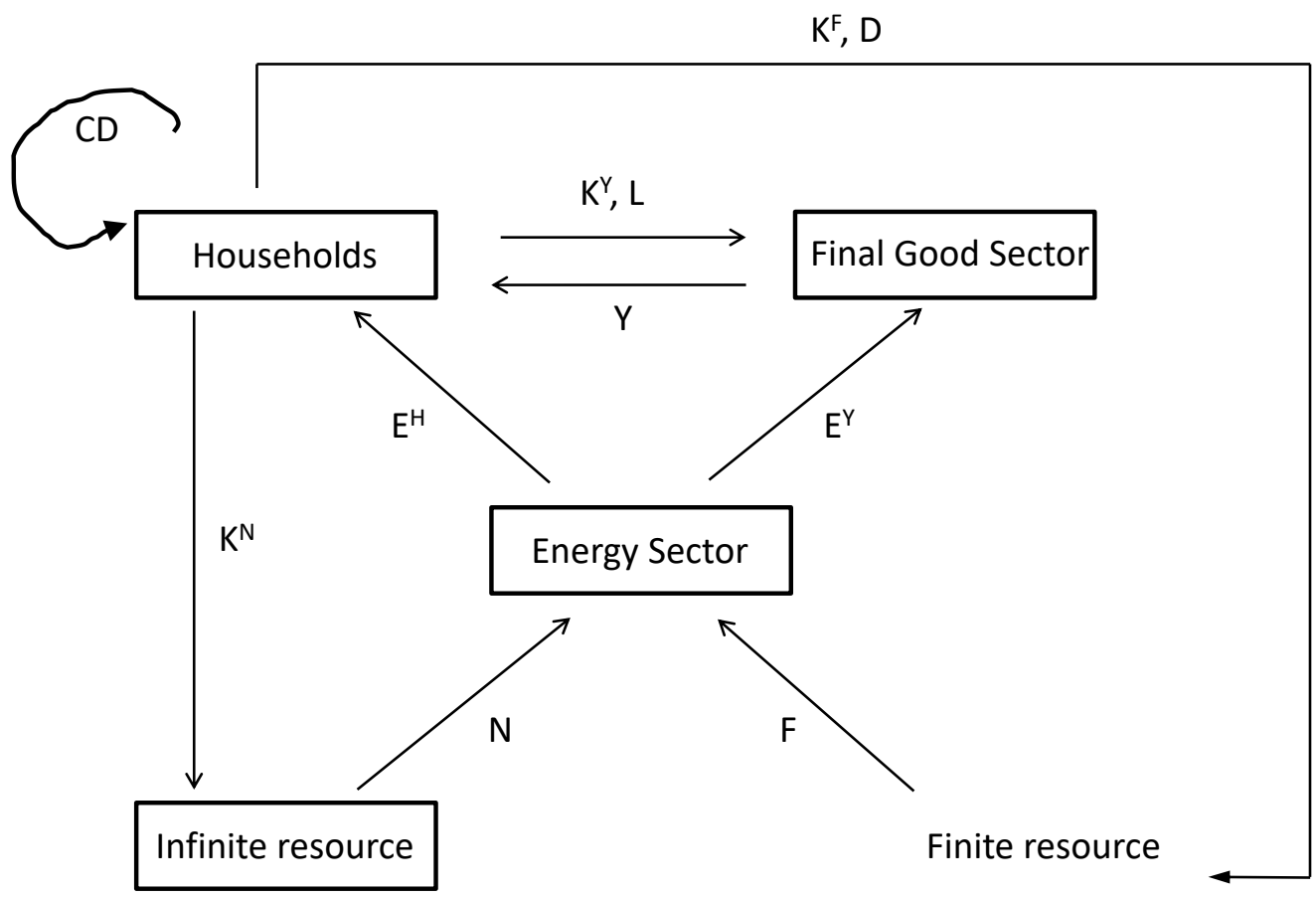

Figure 17: Model overview 
B Priors and posteriors distributions
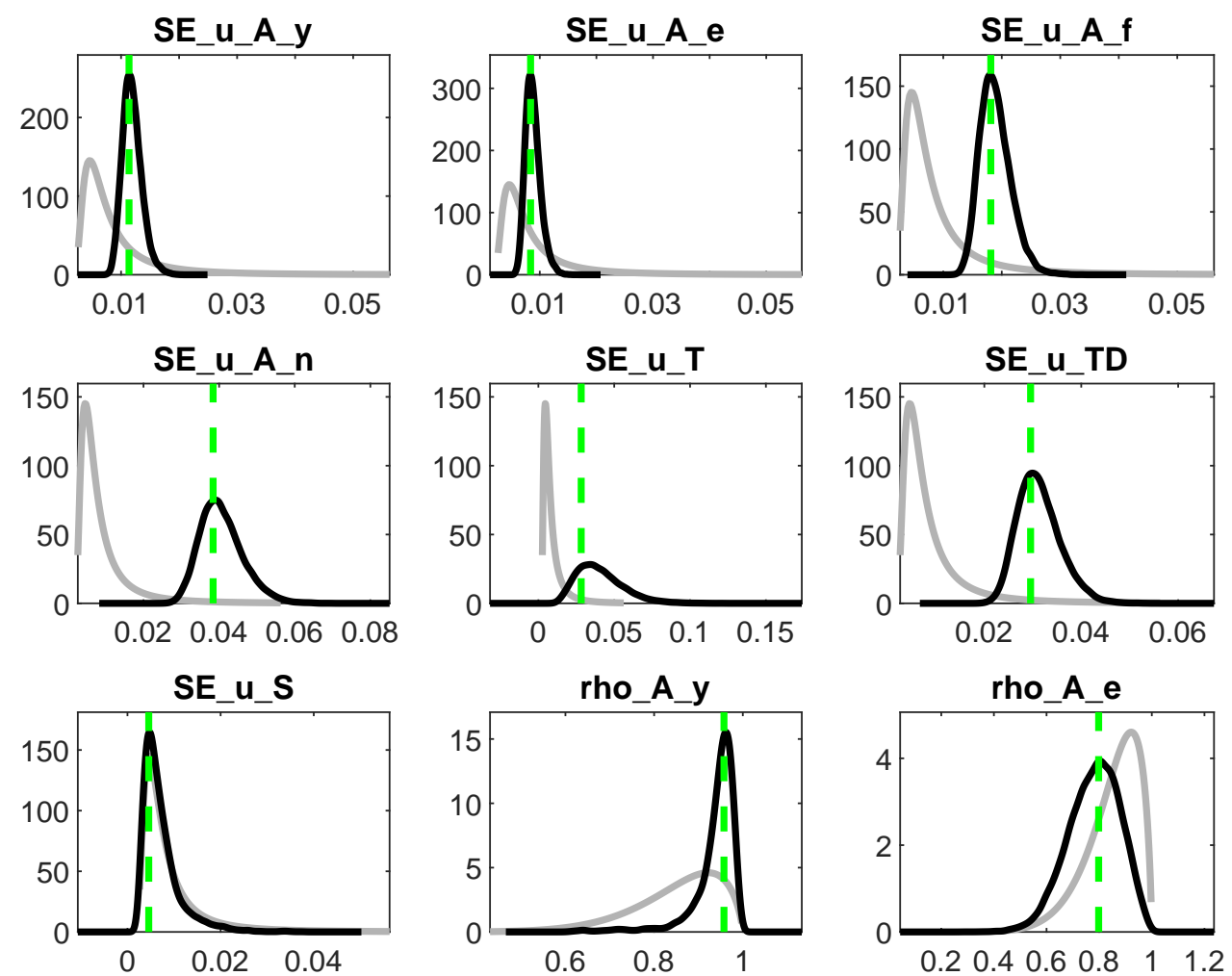

Figure 18: Priors and posteriors.
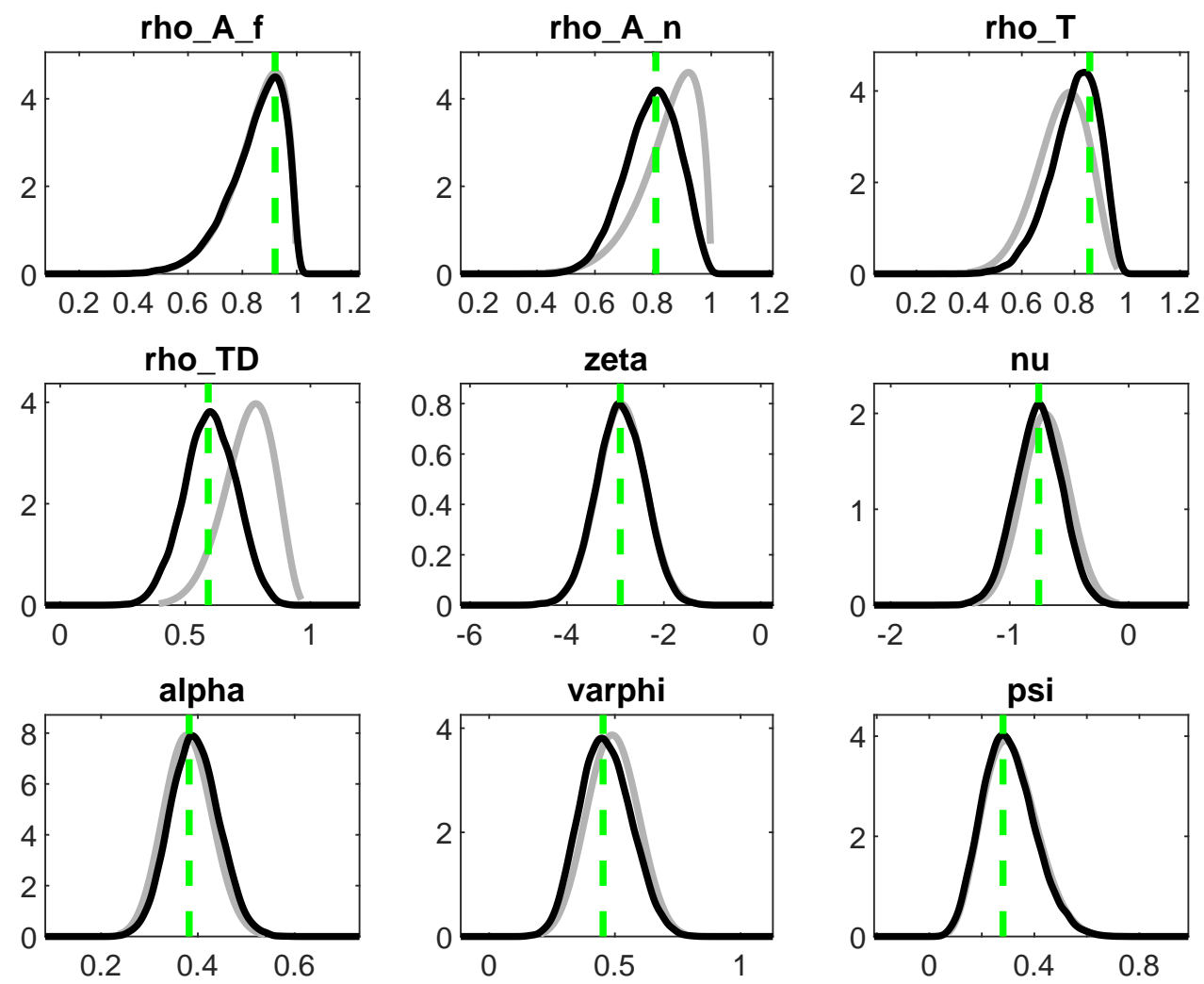

Figure 19: Priors and posteriors. 

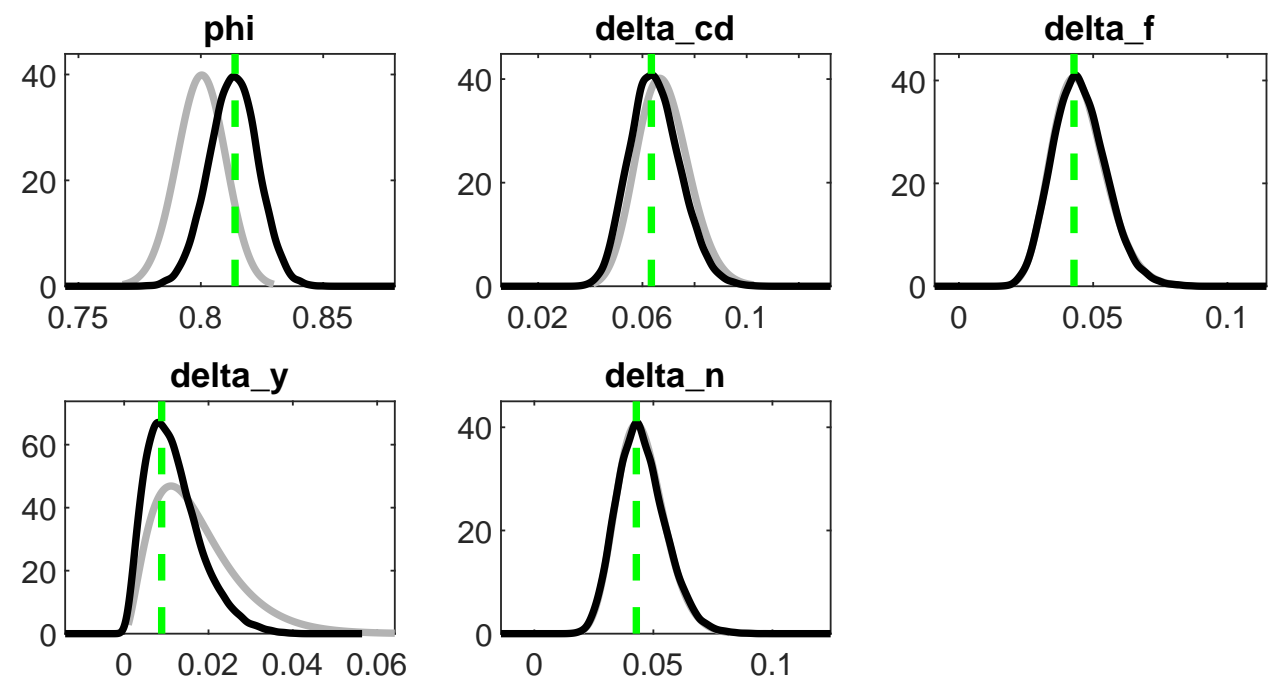

Figure 20: Priors and posteriors.

\section{Variance decomposition of model with replenishment}

Table 8: Posterior mean variance decomposition (in percent)

\begin{tabular}{lcccccccc}
\hline & $u_{-} A_{-} e$ & $u_{-} A_{-} n$ & $u_{-} A_{-} y$ & $u_{-} A_{-} f$ & $u_{-} T$ & $u_{-} S$ & $u_{-} V$ & $u_{-} T D$ \\
\hline$G D P$ & 0.05 & 0.02 & 94.21 & 0.01 & 5.57 & 0.00 & 0.00 & 0.15 \\
$C N$ & 0.01 & 0.00 & 27.53 & 0.00 & 72.42 & 0.00 & 0.00 & 0.03 \\
$C D$ & 0.34 & 0.12 & 50.29 & 0.00 & 31.59 & 0.00 & 0.00 & 17.66 \\
$C$ & 0.03 & 0.01 & 68.64 & 0.00 & 31.21 & 0.00 & 0.00 & 0.11 \\
$E_{-} h$ & 3.87 & 1.33 & 57.88 & 2.35 & 34.43 & 0.00 & 0.01 & 0.13 \\
$L$ & 0.06 & 0.02 & 48.10 & 0.07 & 51.54 & 0.00 & 0.00 & 0.20 \\
$Y$ & 0.04 & 0.01 & 94.15 & 0.04 & 5.59 & 0.00 & 0.00 & 0.16 \\
$E_{-} y$ & 9.95 & 3.39 & 69.70 & 8.56 & 8.09 & 0.00 & 0.01 & 0.29 \\
$F$ & 1.72 & 0.62 & 70.62 & 6.69 & 20.12 & 0.00 & 0.02 & 0.21 \\
$N$ & 0.20 & 83.00 & 11.45 & 0.00 & 5.30 & 0.00 & 0.00 & 0.05 \\
$S$ & 1.09 & 0.41 & 66.00 & 19.34 & 10.59 & 0.19 & 2.30 & 0.09 \\
$K_{-} y$ & 0.03 & 0.01 & 72.36 & 0.00 & 27.06 & 0.00 & 0.00 & 0.54 \\
$K_{-} f$ & 1.62 & 0.56 & 54.41 & 20.32 & 22.01 & 0.10 & 0.73 & 0.25 \\
$K \_n$ & 1.38 & 0.49 & 63.70 & 0.00 & 34.11 & 0.00 & 0.00 & 0.32 \\
$P \_e$ & 40.46 & 13.70 & 9.29 & 36.07 & 0.42 & 0.00 & 0.05 & 0.00 \\
$P \_f$ & 12.49 & 4.03 & 10.55 & 72.70 & 0.13 & 0.00 & 0.11 & 0.00 \\
$P \_n$ & 3.04 & 64.07 & 26.07 & 3.46 & 3.33 & 0.00 & 0.00 & 0.04 \\
$R_{-} y$ & 0.22 & 0.07 & 61.28 & 0.21 & 37.94 & 0.00 & 0.00 & 0.28 \\
\hline & & & & & & $($ Continued on next page) \\
\hline
\end{tabular}


Table 8: (continued)

\begin{tabular}{lcccccccc} 
& $u_{-} A_{-} e$ & $u_{-} A_{-} n$ & $u_{-} A_{-} y$ & $u_{-} A_{-} f$ & $u_{-} T$ & $u_{-} S$ & $u_{-} V$ & $u_{-} T D$ \\
\hline$R_{-} f$ & 12.74 & 4.11 & 10.41 & 72.64 & 0.09 & 0.00 & 0.00 & 0.00 \\
$R_{-} n$ & 12.96 & 4.19 & 42.19 & 17.44 & 23.05 & 0.00 & 0.00 & 0.16 \\
$W$ & 0.03 & 0.01 & 81.61 & 0.01 & 18.23 & 0.00 & 0.00 & 0.12 \\
$A_{-} y$ & 0.00 & 0.00 & 100.00 & 0.00 & 0.00 & 0.00 & 0.00 & 0.00 \\
$A_{-} e$ & 100.00 & 0.00 & 0.00 & 0.00 & 0.00 & 0.00 & 0.00 & 0.00 \\
$A_{-} f$ & 0.00 & 0.00 & 0.00 & 100.00 & 0.00 & 0.00 & 0.00 & 0.00 \\
$A_{-} n$ & 0.00 & 100.00 & 0.00 & 0.00 & 0.00 & 0.00 & 0.00 & 0.00 \\
$A_{-} u$ & 0.00 & 0.00 & 0.00 & 0.00 & 0.00 & 100.00 & 0.00 & 0.00 \\
$E$ & 6.94 & 2.38 & 65.63 & 5.26 & 19.58 & 0.00 & 0.01 & 0.20 \\
$I_{-} c d$ & 0.43 & 0.14 & 2.41 & 0.00 & 12.05 & 0.00 & 0.00 & 84.97 \\
$I_{-} y$ & 0.07 & 0.02 & 27.99 & 0.04 & 30.51 & 0.00 & 0.00 & 41.35 \\
$I_{-} f$ & 8.69 & 2.84 & 8.91 & 70.98 & 6.40 & 0.91 & 0.02 & 1.25 \\
$I_{-} n$ & 24.59 & 8.12 & 18.28 & 0.01 & 43.63 & 0.00 & 0.00 & 5.37 \\
$V$ & 0.25 & 0.10 & 56.32 & 0.09 & 11.81 & 0.80 & 30.56 & 0.06 \\
$D$ & 4.60 & 1.54 & 42.63 & 37.65 & 6.32 & 6.92 & 0.00 & 0.34 \\
$C O$ & 4.60 & 1.54 & 42.63 & 37.65 & 6.32 & 6.92 & 0.00 & 0.34 \\
\hline
\end{tabular}

\section{Math}

\section{E Calculation of Steady States}

\begin{tabular}{c|c|c|c} 
in 2010 & oil & gas & coal \\
\hline exploration & 3.4 & 18 & 24.2 \\
reserves & 37 & 218 & 118 \\
resources & 40 & 150 & 82947 \\
\hline$F / S$ & 0.0919 & 0.0826 & 0.2051
\end{tabular}

Based on the heating values, Germany has a exploration of energy in XX equal to

\begin{tabular}{c|c|c|c} 
oil (HW: 42.8) & gas (HW: 38) & coal (HW: 20) & total \\
\hline 145.52 & 684 & 484 & 131.52
\end{tabular}

Total F/S-share: 0.1287 


\section{F Derivation of business cycles}
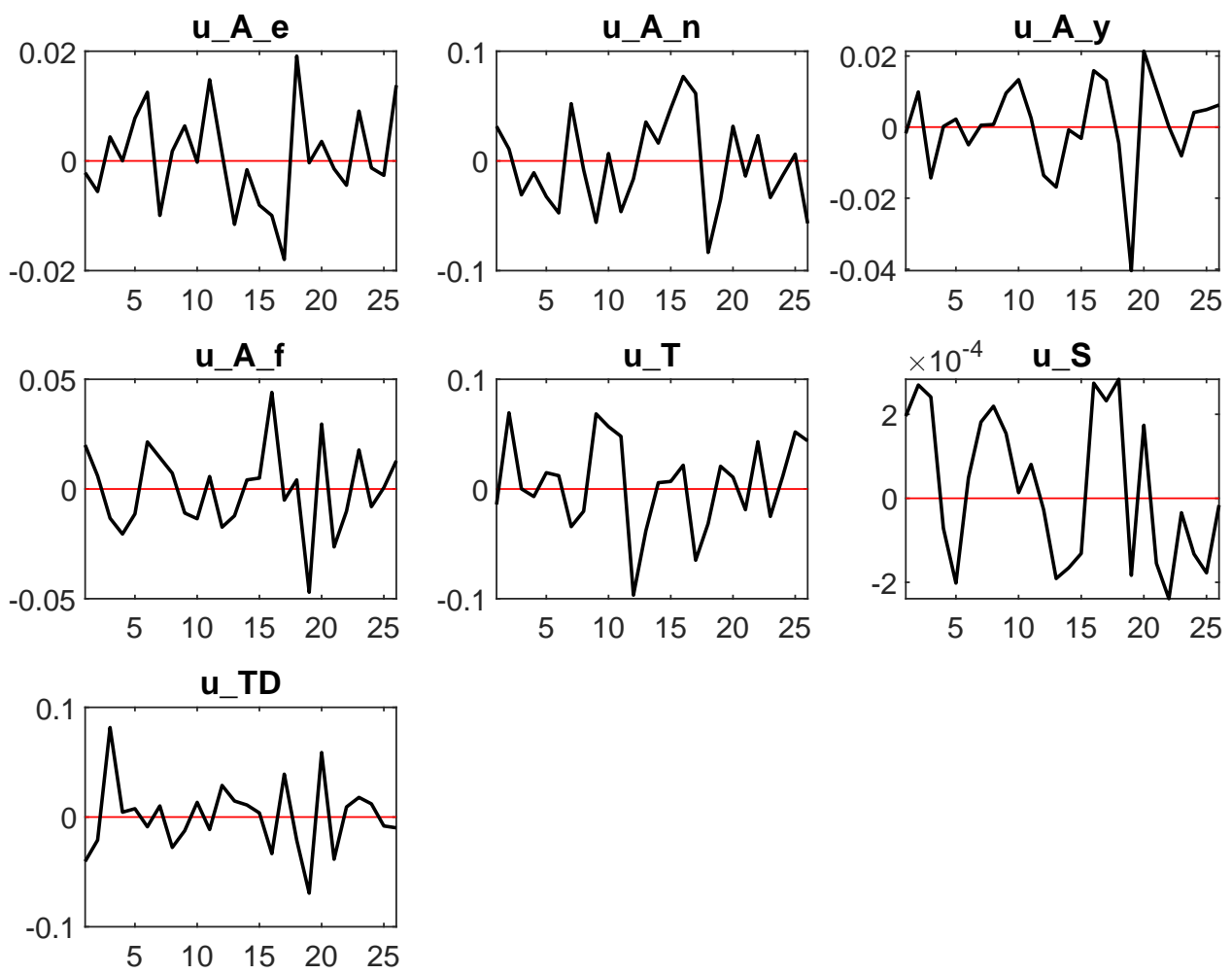

Figure 21: Smoothed shocks. 